University of

Portsmouth

Working Papers in Economics \& Finance

2019-07

EMU-Risk Synchronisation and Financial Fragility Through the Prism of Dynamic Connectedness

Ioannis Chatziantoniou, Portsmouth Business School

David Gabauer, Webster Vienna Private University \& Johannes Kepler University 


\title{
EMU Risk-Synchronisation and Financial Fragility Through the Prism of Dynamic Connectedness
}

\author{
Ioannis Chatziantoniou ${ }^{\dagger}$ and David Gabauer ${ }^{\ddagger}$, \\ $\dagger^{\dagger}$ Economics and Finance Subject Group, University of Portsmouth, Portsmouth Business School, Portland Street, \\ Portsmouth, PO1 3DE, United Kingdom. \\ $¥$ Institute of Applied Statistics, Johannes Kepler University, Altenbergerstraße 69, 4040 Linz, United Kingdom. \\ $\S$ Department of Business and Management, Webster Vienna Private University, Praterstraße 23, 1020 Vienna, Austria.
}

\begin{abstract}
This study employs dynamic connectedness as a measure of financial risk synchronization considering government bond yields in 11 EMU member states. In particular, large values of the relevant index can be an indication of comparable levels of risk further implying that the common currency area consists of a financially sensible set of countries. By contrast, small connectedness values can be an indication of fragmentation whereupon certain countries are considered to be safer than others. The latter would be detrimental for the EMU as it fuels financial fragility, which practically stipulates that crises occur as a result of self-fulfilling market fears. The results are based on a daily dataset which spans between 1st September 2003 and 31st August 2018. Findings show that fragmentation was present at the height of the European sovereign debt crisis and that the interconnectedness has not yet reverted to its pre-2009 levels. In addition, core countries appear to transmit shocks to periphery countries although, occasionally, there are noteworthy disparities. Further investigating these disparities on a pairwise connectedness level - which helps to identify sensible pairs of countries in terms of financial risk - shows that core countries dominate this exercise, with the exception of the bilateral relation between Italy and Spain. The fact that most periphery countries of our sample are not included in these pairs raises concerns and calls for a more substantial integration.
\end{abstract}

Keywords: OCA; ERM II; EMU; Fragmentation; Fragility Hypothesis.

JEL codes: C32; C50; F15; F33; F36; F45. 


\section{Introduction}

Ever since the days of the Treaty that enacted the European Coal and Steel Community $(E C S C)$ in the 1950s, European countries have actively sought ways to collaborate effectively within an environment that promoted lasting peace and prosperity. A common market that allowed free movement of certain products was regarded at the time as a crucial factor for closer partnership and stronger economic development. These efforts further intensified in the years that followed and culminated with the Maastricht Treaty in 1991 and the establishment of the Economic and Monetary Union (EMU). The Euro was officially introduced in January 2002 and at the time of writing, the common currency area counts 19 member states. In the light of these developments and in view of further expansion of the EMU, researchers, politicians and economic agents have been very keen on revisiting the Optimal Currency Area $(O C A)$ requisite conditions (Mundell, 1961; McKinnon, 1963) in order to assess the extent of integration among partners and to identify potential sources of financial turbulence.

Unequivocally, integration issues gained much prominence in the light of the recent European debt crisis (2010), when European authorities had to develop economic adjustment programmes for a number of economies of the European South. The Stability and Growth Pact $(S G P)$ that was initially introduced in the late 1990s to promote fiscal synchronisation across EMU member states proved to be insufficient to prevent the said crisis. What is more, authorities had to lift the 'no bailout' clause of the Lisbon Treaty and the European Central Bank $(E C B)$ had to act as a lender of last resort for escalating turbulence to eventually ease off. Subsequently, the capacity of EMU to act as an OCA has been under heavy criticism since, while at the same time, the importance of further economic and political integration has also been brought to the fore.

The poor performance of the EMU as an OCA has been thoroughly discussed by authors such as O'Rourke and Taylor (2013), Eichengreen (2014), as well as De Grauwe (2016). Some of the topics that recur regarding the discussion around OCAs and the European sovereign debt crisis include, among others, the sudden stop of increased capital flows from the core to the periphery (i.e., following the rise of market uncertainty and doubts regarding the sustainability of this model), the excessive current account im- 
balances across countries, the necessity of a banking union and a common supervisor to oversee the financial system, ECB's role as a lender of last resort, mechanisms for restructuring national debt when the latter is practically unsustainable, both obstacles (e.g., acknowledgement of skills obtained abroad) and consequences (e.g., brain-drain) of labour mobility, as well as, a clear path towards the fiscal and political union. In turn, this study focuses on market uncertainty and perceived risk by investors. We strongly believe that the future prospect of an OCA is closely related to market expectations in connection with financial risk and that reassuring markets that EMU economies are progressively integrating would help avert future crises.

In this regard, our study is primarily concerned with the extent of sovereign bond yield convergence across the Euro Area. It should be noted at this point though, that methodologically, our paper deviates from standard empirical approaches employed in the relevant literature (see, inter alia, Antonakakis et al., 2017; Ehrmann and Fratzscher, 2017; Reboredo and Ugolini, 2015; Caporin et al., 2018). As we further discuss below, we focus on dynamic connectedness (see, Diebold and Yllmaz, 2014) and further introduce refined measures of the latter. In this regard, our method investigates a rather crucial topic from a different angle, considering bond-synchronisation as an indicator of financial risk convergence within the EMU.

What is more, our paper is a good fit of the literature that investigates spillovers across EMU sovereign debt and further purports to explore how decision making within the EMU affects financial risk. There is a wealth of literature that investigates government bond convergence (i.e., studies that mainly utilise yields, spreads or credit default swaps on sovereign debt). Indicatively we quote Christiansen (2014), Falagiarda and Reitz (2015), Reboredo and Ugolini (2015), Bhatt et al. (2017), Ehrmann and Fratzscher (2017), as well as, Afonso et al. (2018) among others. The general consensus that emerges from these studies is that prior to the sovereign debt crisis of 2010 there was increased convergence of bond yields across the Euro Area, which deteriorated at the onset of the crisis. At the same time, ECB's intervention in the summer of 2012 was paramount in restoring (i.e., to a great extent) confidence in the markets, thereby facilitating the convergence of financial risk across EMU member states. 
Another related strand of the literature utilises findings relating to financial risk convergence in order to propose some insightful clustering (i.e., convergence groups) of the countries involved. According to Antonakakis et al. (2017) identifying convergence clubs is important as it allows for investigating the long run common trend of EMU member states, as opposed to limiting the analysis to the customary core versus periphery approach. On a parallel note, authors such as Basse (2014) investigate whether the very composition of core and periphery countries remains fixed over time and especially in the light of developments in the sovereign bond market. Interestingly enough, in most cases the resulting classification will deviate from the customary distinction. Our study further utilises results pertaining to dynamic pairwise connectedness to further investigate convergence groups within our sample.

Finally, our study is also related to the work of authors such as De Grauwe (2013), De Grauwe and Ji (2013), as well as, Saka et al. (2015) who emphasise that changes in the perception of risk revolving around sovereign debt could be put down to selffulfilling dynamics in the sense that, the decoupling of yields (or of spreads, etc.) might be indicative of decoupling of macroeconomic fundamentals (i.e., the Eurozone fragility hypothesis). Within the framework of our analysis potential decoupling of connectedness across EMU member states would be detrimental for the future of the Euro Area as it could potentially fuel a new series of financial crises.

With these in mind, the objective of this study is threefold. First, we investigate patterns of connectedness across countries throughout the period of analysis in order to elucidate issues pertaining to risk synchronisation and fragmentation. Second, we shed light into specific events that inject uncertainty into the market and discuss the corresponding responses by member states, distinguishing countries into net transmitters and net receivers of shocks. Third, on the basis of pairwise connectedness, we identify pairs that would potentially constitute sensible candidates for a monetary union. It should be noted that, in close relation to this discussion, the European Commission (2017) has recently issued a White Paper on the Future of Europe investigating various future scenarios and whether (and how far) integration should go beyond the Single Market. We strongly believe that our framework of analysis, which assesses financial risk synchronisation across 
member states, allows for an explicit answer on whether countries should do less together, or more.

To this end, we utilize daily data on sovereign bond yields for a period spanning from 1st September 2003 to 31st August 2018. We collect data on 6 core and 5 periphery EMU countries; namely, Austria, Belgium, Finland, France, Germany, the Netherlands, Greece, Ireland, Italy, Portugal and Spain. In turn, we obtain results from a time-varying parameters vector autoregression (TVP-VAR) based dynamic connectedness approach (Antonakakis and Gabauer, 2017; Korobilis and Yilmaz, 2018) which practically constitutes a refined version of the rolling-window VAR based dynamic connectedness approach of Diebold and Yilmaz (2014) $)^{1}$.

This specific framework of analysis allows for two main contributions. The first one relates to the employment of connectedness as a measure of financial risk coordination. To the best of our knowledge this is an angle that has not been investigated by existing literature. The second contribution relates to the investigation of financial risk coordination by utilizing an empirical method which refines typical measurement-deficiencies of the standard rolling windows approach such as (i) the arbitrary choice of the forecast horizon and the window length, (ii) the distorting effect of outliers that are inevitably included, as well as (iii), the subsequent loss of observations as we move across windows.

Main findings indicate that interconnectedness across EMU member states is much stronger prior to 2009. In addition, there is strong evidence of fragmentation at the height of the crisis, while, in the post-2012 period interconnectedness intensifies without reverting though to its initial pre-2009 levels. Furthermore, net pairwise connectedness results indicate that the core transmits shocks to the periphery; however, there are sharp contrasts among core countries, while, the net transmission results are also highly eventdependent. In order to shed additional light to the inherent disparities in the transmission of connectedness across EMU countries we proceed with a classification of pairs of coun-

\footnotetext{
${ }^{1}$ The estimation procedure relies on a generalised connectedness framework whereby, contrary to the orthogonalised connectedness approach, results are invariant of the variable ordering. We further opine, that an orthogonalised framework of analysis would be inappropriate in this study, given that there appears to be no underlying theoretical framework that describes structural relationships among daily bond yields. In this regard, in line with the existing seminal literature on connectedness (Diebold and Yilmaz, 2009, 2012, 2014), we are referring to spillover "shocks"; however, it should be noted, that these shocks are not similar to the structural macroeconomic shocks that we encounter in the relevant macroeconomic literature.
} 
tries by virtue of financial risk coordination. We find that core countries are clearly better candidates for participating in a common currency area. Findings have obvious policy implications in connection with the role of the ECB, the development of institutions, internal capacity and financial fragility in EMU, as well as, the extent of European economic and political integration.

The remainder of this study is organised as follows: Section 2 presents information with regard to the employed data and empirical methods. Then, Section 3 proceeds with the exposition and interpretation of the relevant findings. Section 5 concludes the study.

\section{Data and Methods}

\subsection{Summary Statistics}

This study is based on a daily dataset which consists of 11 core and periphery EMU sovereign bond yields retrieved from Datastream. The sample countries can be split up in 6 core countries, Austria, Belgium, Finland, France, Germany and the Netherlands and in 5 periphery EMU countries, Greece, Ireland, Italy, Portugal and Spain. Our data spans over the period from 1st September 2003 to 31st August 2018.

Figure 1 illustrates the relevant sovereign bond yields. Notably, strong co-movement is evident in the pre-2009 period and particularly before the onset of the Global Financial Crisis. From that point on, we note that government bond yields exhibit disparate movements which diverge significantly until the European governmental debt crisis (2010). Focusing on Greece, another divergence pattern can be observed in the beginning of 2015 . Note that Greece entering a third economic adjustment programme in 2015 strengthened bond convergence with other EMU member states. Since government bond yields are considered to be unit root processes according to the unit root test statistics proposed by Stock et al. (1996), we can analyze the first differenced series, $y_{i t}=x_{i t}-x_{i t-1}$. This is shown in Figure 2.

[Insert Figures 1 and 2 around here]

In turn, as can be seen in Table 1, all means and medians - except for Greece - are negative which in turn means that the trend for all sovereign bond yields has been negative 
over time. In addition, the volatility of sovereign bond yields of the periphery countries is much higher compared to that of the core countries. We find that the sovereign bond yields of all periphery countries, except for Portugal, are negatively skewed whereas all core countries exhibit positively skewed bond yields. Those differences aside, all series are significantly leptokurtic, non-normally distributed, stationary, autocorrelated and exhibit $\mathrm{ARCH} / \mathrm{GARCH}$ errors. On a final note, we find that unconditional correlations across core countries are highest whereas the correlation across periphery countries and between periphery and core countries are moderately high to low. Interestingly, Greek bond yield movements seem to be independent or even slightly negatively correlated with other EMU bond yields.

[Insert Table 1 around here]

\section{$2.2 \quad$ TVP-VAR based Dynamic Connectedness Approach}

To accurately estimate the transmission mechanism of the Euro Area's sovereign bond yields we base the dynamic connectedness measures (Diebold and Yllmaz, 2014) on the estimation results of a TVP-VAR with time-varying covariances (Koop and Korobilis, 2014). This combined methodology overcomes the burden of (i) lossing valuable observations, (ii) choosing - in most cases rather arbitrarily - a rolling-window size and (iii) outlier sensitivity as stressed out by Antonakakis and Gabauer (2017) and Korobilis and Yilmaz (2018). According to the Bayesian information criterion (BIC), we are employing a TVP-VAR with one lag which can be formulated as follows,

$$
\begin{aligned}
\boldsymbol{x}_{t} & =\boldsymbol{\Phi}_{t} \boldsymbol{x}_{t-1}+\boldsymbol{\epsilon}_{t} & \boldsymbol{\epsilon}_{t} \mid \boldsymbol{\Omega}_{t-1} \sim N\left(\mathbf{0}, \boldsymbol{\Sigma}_{t}\right) \\
\operatorname{vec}\left(\boldsymbol{\Phi}_{t}\right) & =\operatorname{vec}\left(\boldsymbol{\Phi}_{t-1}\right)+\boldsymbol{\xi}_{t} & \boldsymbol{\xi}_{t} \mid \boldsymbol{\Omega}_{t-1} \sim N\left(\mathbf{0}, \boldsymbol{\Xi}_{t}\right)
\end{aligned}
$$

where $\boldsymbol{\Omega}_{t-1}$ illustrates all available information until $t-1, \boldsymbol{x}_{t}, \boldsymbol{x}_{t-1}$, and $\boldsymbol{\epsilon}_{t}$ are $m \times 1$ vectors, and $\boldsymbol{\Phi}_{t}$ and $\boldsymbol{\Sigma}_{t}$ are $m \times m$ dimensional matrices. Furthermore, vec $\left(\boldsymbol{\Phi}_{t}\right)$ and $\boldsymbol{\xi}_{t}$ are $m^{2} \times 1$ dimensional vectors and $\boldsymbol{\Xi}_{t}$ is an $m^{2} \times m^{2}$ dimensional matrix.

For the initialization of the Kalman Filter we are using the Primiceri (2005) prior. Hence, in our study we set $\boldsymbol{\Phi}_{O L S}, \boldsymbol{\Sigma}_{O L S}^{\Phi}$ and $\boldsymbol{\Sigma}_{O L S}$ equal to the VAR estimation results 
of the first 250 days Korobilis and Yilmaz (2018):

$$
\begin{aligned}
\operatorname{vec}\left(\boldsymbol{\Phi}_{0}\right) & \sim N\left(\operatorname{vec}\left(\boldsymbol{\Phi}_{O L S}\right), \boldsymbol{\Sigma}_{O L S}^{\Phi}\right) \\
\boldsymbol{\Sigma}_{0} & =\boldsymbol{\Sigma}_{O L S}
\end{aligned}
$$

Due to numerical stability we decided to implement decay factors in the Kalman Filter algorithm. The choice of decay factors resembles the choice of priors in general and depends on the expected amount of time-variation in the parameters. Since this study analyzes daily data the benchmark model is based on $\kappa_{1}=0.99$ and $\kappa_{2}=0.99^{2}$. Hence, the multivariate Kalman Filter can be formulated as follows:

$$
\begin{aligned}
\operatorname{vec}\left(\boldsymbol{\Phi}_{t}\right) \mid \boldsymbol{x}_{1: t-1} & \sim N\left(\operatorname{vec}\left(\boldsymbol{\Phi}_{t \mid t-1}\right), \boldsymbol{\Sigma}_{t \mid t-1}^{\Phi}\right) \\
\boldsymbol{\Phi}_{t \mid t-1} & =\boldsymbol{\Phi}_{t-1 \mid t-1} \\
\boldsymbol{\epsilon}_{t} & =\boldsymbol{x}_{t}-\boldsymbol{\Phi}_{t \mid t-1} \boldsymbol{x}_{t-1} \\
\boldsymbol{\Sigma}_{t} & =\kappa_{2} \boldsymbol{\Sigma}_{t-1 \mid t-1}+\left(1-\kappa_{2}\right) \boldsymbol{\epsilon}_{t}^{\prime} \boldsymbol{\epsilon}_{t} \\
\boldsymbol{\Xi}_{t} & =\left(1-\kappa_{1}^{-1}\right) \boldsymbol{\Sigma}_{t-1 \mid t-1}^{\Phi} \\
\boldsymbol{\Sigma}_{t \mid t-1}^{\Phi} & =\boldsymbol{\Sigma}_{t-1 \mid t-1}^{\Phi}-\boldsymbol{\Xi}_{t} \\
\boldsymbol{\Sigma}_{t \mid t-1} & =\boldsymbol{x}_{t-1} \boldsymbol{\Sigma}_{t \mid t-1}^{\Phi} \boldsymbol{x}_{t-1}^{\prime}+\boldsymbol{\Sigma}_{t}
\end{aligned}
$$

We update $\boldsymbol{\Phi}_{t}, \boldsymbol{\Sigma}_{t}^{\Phi}$ and $\boldsymbol{\Sigma}_{t}$ given the information at time $t$ by the following steps:

$$
\begin{aligned}
\operatorname{vec}\left(\boldsymbol{\Phi}_{t}\right) \mid \boldsymbol{x}_{1: t} & \sim N\left(\operatorname{vec}\left(\boldsymbol{\Phi}_{t \mid t}\right), \boldsymbol{\Sigma}_{t \mid t}^{\Phi}\right) \\
\boldsymbol{K}_{t} & =\boldsymbol{\Sigma}_{t \mid t-1}^{\Phi} \boldsymbol{x}_{t-1}^{\prime} \boldsymbol{\Sigma}_{t \mid t-1}^{-1} \\
\boldsymbol{\Phi}_{t \mid t} & =\boldsymbol{\Phi}_{t \mid t-1}+\boldsymbol{K}_{t}\left(\boldsymbol{x}_{t}-\boldsymbol{\Phi}_{t \mid t-1} \boldsymbol{x}_{t-1}\right) \\
\boldsymbol{\Sigma}_{t \mid t}^{\Phi} & =\left(\boldsymbol{I}-\boldsymbol{K}_{t}\right) \boldsymbol{\Sigma}_{t \mid t-1}^{\Phi} \\
\boldsymbol{\epsilon}_{t \mid t} & =\boldsymbol{x}_{t}-\boldsymbol{\Phi}_{t \mid t} \boldsymbol{x}_{t-1} \\
\boldsymbol{\Sigma}_{t \mid t} & =\kappa_{2} \boldsymbol{\Sigma}_{t-1 \mid t-1}+\left(1-\kappa_{2}\right) \boldsymbol{\epsilon}_{t \mid t}^{\prime} \boldsymbol{\epsilon}_{t \mid t}
\end{aligned}
$$

\footnotetext{
${ }^{2}$ Keep in mind that this specification allows for more monthly parameter variability compared to Koop and Korobilis (2014). In addition, fixed decay factors have been used as time-varying decay factors are substantially increasing the computation burden of the algorithm and since the value added with respect to the forecast performance is questionable (Koop and Korobilis, 2013). Robustness checks based on various decay factor combinations are provided.
} 
where $\boldsymbol{K}_{t}$ represents the Kalman Gain that explains by how much the parameters, $\boldsymbol{\Phi}_{t}$, should be changed in a given state. On the one hand, if the parameter uncertainty, $\Sigma_{t \mid t-1}^{\Phi}$, is small (large) it means that the parameters, $\boldsymbol{\Phi}_{t}$, should be similar to (adjusted) their prior states. On the other hand, if the error variance $\boldsymbol{\Sigma}_{t}$ is small (large) - meaning that the estimation is very accurate (inaccurate) - the parameters, $\boldsymbol{\Phi}_{t}$, should be similar to (adjusted) their prior values.

After we have estimated the time-varying parameters, we need to transform the TVPVAR to a TVP-VMA using the Wold representation theorem, $\boldsymbol{x}_{t}=\sum_{i=1}^{p} \boldsymbol{\Phi}_{i t} \boldsymbol{x}_{t-i}+\boldsymbol{\epsilon}_{t}=$ $\sum_{j=1}^{\infty} \Lambda_{j t} \boldsymbol{\epsilon}_{t-j}+\boldsymbol{\epsilon}_{t}$. In a next step, the TVP-VMA coefficients are extracted to calculate the generalised forecast error variance decomposition (GFEVD) (Koop et al., 1996; Pesaran and Shin, 1998) on which the dynamic connectedness framework (Diebold and Yllmaz, 2014) is built on.

To compute all dynamic connectedness measures seven steps are required.

Step I: The (scaled) GFEVD, $\tilde{\psi}_{i j, t}^{g}(K)$ - representing the pairwise directional connectedness from $j$ to $i$ which in turn is the influence variable $j$ has on variable $i$ in terms of its forecast error variance share - is defined as follows:

$$
\psi_{i j, t}^{g}(K)=\frac{\sum_{i i, t}^{-1} \sum_{t=1}^{K-1}\left(\boldsymbol{\iota}_{i}^{\prime} \boldsymbol{\Lambda}_{K, t} \boldsymbol{\Sigma}_{t} \boldsymbol{\iota}_{j}\right)^{2}}{\sum_{j=1}^{m} \sum_{t=1}^{K-1}\left(\boldsymbol{\iota}_{i} \boldsymbol{\Lambda}_{K, t} \boldsymbol{\Sigma}_{t} \boldsymbol{\Lambda}_{K, t}^{\prime} \boldsymbol{\iota}_{i}\right)} \quad \tilde{\psi}_{i j, t}^{g}(K)=\frac{\psi_{i j, t}^{g}(K)}{\sum_{j=1}^{m} \psi_{i j, t}^{g}(K)}
$$

with $\sum_{j=1}^{m} \tilde{\psi}_{i j, t}^{g}(K)=1$ and $\sum_{i, j=1}^{m} \tilde{\psi}_{i j, t}^{g}(K)=m$, where $K$ represents the forecast horizon and $\boldsymbol{\iota}_{i}$ a selection vector with a one on the $i$ th position and zero otherwise.

Step II: The total directional connectedness TO others measures how much of a shock in variable $i$ is transmitted to all other variables $j$ :

$$
C_{i \rightarrow j, t}^{g}(K)=\frac{\sum_{j=1, i \neq j}^{m} \tilde{\psi}_{j i, t}^{g}(K)}{\sum_{j=1}^{m} \tilde{\psi}_{j i, t}^{g}(K)}
$$

Step III: The total directional connectedness FROM others measures how much variable $i$ is receiving from shocks in all other variables $j$ :

$$
C_{i \leftarrow j, t}^{g}(K)=\frac{\sum_{j=1, i \neq j}^{m} \tilde{\psi}_{i j, t}^{g}(K)}{\sum_{i=1}^{m} \tilde{\psi}_{i j, t}^{g}(K)}
$$

Step IV: The net total directional connectedness represents the difference between the 
total directional connectedness TO others and the total directional connectedness FROM others, which can be interpreted as the influence variable $i$ has on the analyzed network.

$$
C_{i, t}^{g}=C_{i \rightarrow j, t}^{g}(K)-C_{i \leftarrow j, t}^{g}(K)
$$

If the $C_{i, t}^{g}>0\left(C_{i, t}^{g}<0\right)$ variable $i$ is considered as a net transmitter (receiver) since it is influencing all others more (less) than being influenced by them.

Step V: The net pairwise directional connectedness (NPDC) provides us with information about the bilateral transmission process between variable $i$ and variable $j$ :

$$
N P D C_{i j}(K)=\tilde{\psi}_{j i t}(K)-\tilde{\psi}_{i j t}(K)
$$

If $N P D C_{i j}(K)>0\left(N P D C_{i j}(K)<0\right)$ variable $i$ is driving (driven by) variable $j$.

Step VI: Traditionally the total connectedness index (TCI) expresses the average amount of one variable's forecast error variance share explained by all other variables:

$$
C_{t}^{g}(K)=\frac{\sum_{i, j=1, i \neq j}^{m} \tilde{\psi}_{i j, t}^{g}(K)}{m}
$$

Based on Monte Carlo simulations it can be shown that the own variance shares are by construction always larger or equal to all cross variance shares ${ }^{3}$. This means that this TCI is ranging between $\left[0, \frac{m-1}{m}\right]$. Since we want to know the average amount of network co-movement in percent - which should range between $[0,1]$ - we have to slightly adjust the TCI:

$$
C_{t}^{g}(K)=\frac{\sum_{i, j=1, i \neq j}^{m} \tilde{\psi}_{i j, t}^{g}(K)}{m-1} \quad 0 \leq C_{t}^{g}(K) \leq 1 .
$$

Step VII: The pairwise connectedness index (PCI) measures the interconnectedness between variable $i$ and $j$ - which is masked by the TCI - and can be written as:

$$
C_{i j t}^{g}(K)=2\left(\frac{\tilde{\psi}_{i j, t}^{g}(K)+\tilde{\psi}_{j i, t}^{g}(K)}{\tilde{\psi}_{i i, t}^{g}(K)+\tilde{\psi}_{i j, t}^{g}(K)+\tilde{\psi}_{j i, t}^{g}(K)+\tilde{\psi}_{j j, t}^{g}(K)}\right) \quad 0 \leq C_{i j t}^{g}(K) \leq 1 .
$$

A high (low) PCI suggests high (low) synchronization and thus is indicative of risk equality (inequality). Therefore, it is more (less) likely that variable $i$ and $j$ are in the same

\footnotetext{
${ }^{3}$ Code for Monte Carlo simulation is available upon request.
} 
monetary union.

\section{Empirical Results and Discussion}

\subsection{Overview of Averaged Connectedness Dynamics}

We begin our discussion by providing an overview of the averaged connectedness measures which are depicted in Table 2. It shows that the main transmitter of shocks is Germany followed by the Netherlands, Belgium, Finland, Austria, France, and Italy whereas the net receivers of shocks are Greece followed by Portugal, Ireland and Spain. The same pattern can be observed by looking at the number of net pairwise directional transmission dominance.

In addition, the TCI explains that on average the comovement of the sovereign bond yields and hence the risk equality of the whole network is $83.3 \%$ which in turn means

that on average $75.7 \%\left(=83.3 \% \cdot \frac{10}{11}\right)$ of the forecast error variance of one sovereign bond yield can be explained by the influence of all other sovereign bond yields. In turn, this practically means that this sort of analysis is masking specific episodes (i.e., economic shocks) that have had a distinct impact on the Euro Area and on its interconnectedness. Therefore, the dynamic total connectedness captures the time-variation of the TCI for the full sample period of the study.

[Insert Table 2 around here]

\subsection{Financial Risk Coordination}

In this regard, we focus our analysis on the dynamic total connectedness measure which allows us to trace the interconnectedness of our network over time. These results are given by Figure 3. In particular, we note that prior to 2009 bond yields are highly interconnected; that is, the value of the dynamic total connectedness reaches almost $100 \%$ which in turn, is suggestive of the very strong linkages at the time. Most importantly, the large value of the dynamic total connectedness prior to 2009 is rather indicative of the fact that up to that point EMU member states are regarded as being equally risky. The latter predicates, of course, on the notion that interest paid on sovereign debt is closely related 
to a country's financial health and further reflects risk assessments by rating agencies. Therefore, the broader picture is that the period until 2009 is a relatively tranquil period for the EMU with increased levels of confidence both in the compliance efforts of member states regarding Maastricht's convergence criteria and in the broader prospects of the common market and the monetary union.

[Insert Figure 3 around here]

By contrast, from 2009 onwards, we note that the dynamic total connectedness follows a downward trend, reaching a trough in 2012. As evident in Figure 3, during the year 2012 the dynamic total connectedness experiences its lowest values for the sample period of the study; that is, values in the region between $55 \%$ and $60 \%$. Obviously, this decoupling of bond yield levels is associated with the outbreak of the European debt crisis and the need for European authorities to develop economic adjustment programmes for certain EMU member states, starting with Greece in May 2010. Given notable deviations from the Maastricht criteria, especially in relation to government debt-to-GDP ratio, government budget deficit levels, as well as, mounting uncertainty in relation to the creditworthiness of specific EMU member states, 2009 marks the beginning of an era whereupon, interest rates on sovereign debt start to exhibit sharp contrasts. According to Bølstad and Elhardt (2018) from October 2009 onwards investors in EMU sovereign debt, begin to question the willingness of European institutions to rescue specific economies. On one hand, these economies are ranked low, in terms of fiscal space or capacity to repay their debts (e.g., Greece), however, on the other, these countries had issued debt within the EMU which provided confidence to investors. What is more, our findings of plummeting dynamic total connectedness in the period following the outbreak of the debt crisis in Europe, resonate with authors such as Ehrmann and Fratzscher (2017) and BenSaïda (2018) who put forward the argument that fragmentation - which reflects the effort on behalf of the European authorities to reduce spillovers across markets and protect financially healthy member states from contagion effects stemming from troubled economies - marked the period during the height of the crisis (i.e., early 2010 and until the spring of 2012). In addition, authors such as Beetsma et al. (2017) emphasize the role of decisions made by 
the ECB at the time such as the Securities Markets Programme (SMP) initiated in May 2010 .

Evidentially, dynamic total connectedness appears to be picking up in the period after 2012; nonetheless, it does not revert back to its initial levels, but rather, from 2015 onwards, it narrowly oscillates around the $80 \%$ mark until the most recent dates of our sample period. At this point, it would be instructive to note that the upward trend that commences in 2012 coincides with a period that encompasses two crucial developments that take place within the EMU and help to further promote confidence among economic agents. First, a second programme for Greece is agreed in March 2012, following the rather unsuccessful first programme. Irrespective of whether or not the appropriate mix of measures is again employed regarding the recovery of the Greek economy, this development is considered to be a positive step forward, as it practically underscores the commitment on behalf of the European authorities to resolve the Greek matter. Second, and in close relation to the previous point, in July 2012, the president of the ECB reassures markets by committing to that 'the ECB is ready to do whatever it takes to preserve the Euro'; a statement that clearly fosters confidence and mitigates the eventuality of the default of a member state undergoing financial aid programmes. In further support to the arguments that we put forward and the situation that is illustrated in Figure 3, Afonso et al. (2018) show that following Mario Draghi's statement in July 2012 there is a regime shift in connection with the pricing of European sovereign bonds. The effectiveness of unconventional ECB policies such as the Outright Monetary Transactions $(O M T)$ - announced in September 2012 - is also reported by authors such as Jäger and Grigoriadis (2017) and Roch and Uhlig (2018).

Nonetheless, the rising dynamic total connectedness trend disappears around 2015, mainly reflecting the persistent character of specific imbalances that help preserve uncertainty in European markets. In particular, in the period that begins in 2015, turbulence still remains in Europe and this could be the aftermath of the change in helm of the Greek government (i.e., the January 2015 elections, followed by the referendum in July 2015, as well as, the third economic adjustment programme in August 2015), the political unrest in Spain (i.e., the October 2017 referendum in Catalonia), or the very recent controversies 
of the Italian government with EU officials, over a series of matters (following the March 2018 elections). In point of fact, the slight decrease in the dynamic total connectedness in the most recent months of our sample that is evident in Figure 3, might be capturing these specific developments in Italy. On a final note, it would also be reasonable to assume that, even though the UK is not part of the common currency, the decision to exit the EU (i.e., June 2016 referendum) has played its part in raising European market uncertainty. In this regard, we opine that even though certain problems have been resolved (a fact that helps explain why the dynamic total connectedness has recovered from the low levels of 2012) there are still sources of uncertainty that torment the EMU (justifying perhaps why the dynamic total connectedness has not fully returned to its initial levels; that is, before 2009). Relevant considerations that highlight current problems within the EMU and further relate to the broader question of whether Europe should integrate more or become more fragmented, have also been raised by authors such as Hodson (2017) and Verdun (2018).

These findings are further supported in the following sections where we show that periphery countries have been at the epicenter of these episodes and that connectedness levels with respect to Ireland and Italy recovered faster compared to other periphery countries after the European governmental debt crisis (2010). In this regard, although stressed economies do exhibit a more pronounced or lengthier decline in connectedness, we should not lose sight of the fact that individual differences between core countries or between periphery countries are indeed possible. This point is further emphasized in Sections 3.3 and 3.4 where we discuss net total and net pairwise directional connectedness, respectively. What is more, in Section 3.5 we make use of the pairwise connectedness indices in order to identify potential ideal candidates for putting together a monetary union.

\subsection{The Complicated Nature of Coordination}

In turn, we focus on net total directional connectedness across the EMU countries included in our study. In particular, given that the framework of our analysis facilitates not only the investigation of risk-discrepancies across member states over time, but also, 
the establishment of the source and direction of the shocks that bring forth such discrepancies in the first place; it would be instructive to explore the dynamic process of net connectedness measures across countries.

In this respect, Figure 4 presents results regarding net total directional connectedness across countries. It is important to clarify that positive values correspond to net transmitters of shocks in the sovereign debt market, whereas, negative values reveal net receivers of such shocks. It should also be noted that irrespective of whether a country assumes one role or the other, increased levels of connectedness reflect periods whereupon there is a convergence across countries with respect to sovereign debt level of risk. To put it differently, increased levels of connectedness are indicative of the fact that confidence is progressively being restored in the market or that European authorities have gained some degree of control over the crisis. Nonetheless, wider discussion further revolves around which countries are net transmitters and which are net receivers of shocks in the market for sovereign debt.

\section{[Insert Figure 4 around here]}

As evidenced in Figure 4, despite that certain countries assume one specific role for almost the entirety of the sample period (e.g., Germany or the Netherlands clearly assume a net transmitting role, whereas, Greece is mainly a net receiver), there are many instances where other countries assume both roles (e.g., France or Ireland). This finding is in line with authors such as BenSaïda (2018) who argues that core EMU countries typically affect their peripheral counterparts. A closer look would in fact indicate that Italy (and perhaps Spain to a lesser extent) appear to be an exception to this rule, given perhaps the size of their economies and their global economic influence (Italy is a member of the G7 and Spain a permanent invitee of G20). Notably though, in the case of Greece, Ireland and Portugal, evidence suggests that there is a very limited role deserved for these countries as net transmitters of shocks. To be more explicit, it appears that for most periphery countries, net transmitting capacity coincided with the onset of the sovereign bond crisis in 2010, but also, with time intervals around their agreement on some economic adjustment programme (see, for example, Greece and Ireland in 2010, or, Portugal in 2011). What is more, it is rather obvious that following the outbreak of the crisis, there is a decrease in 
both transmitting and receiving dynamics in periphery countries. This is more pronounced considering Greece, Ireland and Portugal. Clearly in the case of Greece, there is a collapse of said dynamics that stays in place until after Greece's second adjustment programme in 2012. This result might also be associated with the argument put forward by FernándezRodríguez et al. (2016) that during a crisis period, the positive influence of core economies on the periphery is practically lost, given that - as already mentioned in previous sections - economic agents begin to question (i) the actual financial state of the troubled countries and (ii) the extent to which core countries will choose to protect the stressed economies of the periphery (i.e., matters of capacity and willingness).

In turn, with the passing of time and the deployment of the relevant unconventional monetary policy tools Greece, Ireland and Portugal, appear to persistently act as net recipients of shocks. Besides, Bratis et al. (2018) provide an interesting point of view, arguing that after February 2012 core EMU countries started to feel immune against the complications stemming from the Greek economy, which in turn, might help explain why it was not before long that stressed economies reverted back to their initial role as net receivers. Nonetheless, we should stress that Ireland appears to transmit on a net basis again towards the more recent months of our sample; more likely reflecting developments in relation to Brexit, which unequivocally increase market uncertainty.

Another interesting finding illustrated in Figure 4 is that both Austria and Belgium appear to be differently affected compared to other core countries during the height of the European debt crisis. In particular, contrary to other core countries, the net receiving role assumed by both Austria and Belgium during that time interval is rather persistent. This fact, coupled with the observation made earlier that Italy and Spain - probably because of the size of their economy and their economic importance behaved differently vis-a-vis other periphery countries - prompts the question of whether the current classification of EMU countries into core and peripheral is useful to making generalisations when it comes to assessing the effects of a shock in the Euro Area and whether, we could somehow come up with different classifications. 


\subsection{Pairwise Insights}

Turning to the investigation of bilateral connectedness between specific countries, the case of Germany is rather striking in that further investigation of connectedness across member states shows that the picture is not very clear and that generalisations are not always pertinent. In this regard, Figure 5 presents net pairwise connectedness of all EMU member states vis-a-vis Germany which in this case serves as the reference country ${ }^{4}$.

Starting with the years that marked the height of the crisis and in line with previous arguments, during this period, connectedness deteriorates while it is rather evident that most periphery countries receive less from Germany overall. In addition, country-specific results are indicative of sharp contrasts across periphery countries. For instance, Greece appears to receive around the time when some adjustment programme was in place (e.g., May 2010, March 2012, as well as, August 2015). Nonetheless, there is no improvement after that given that Greece only exited the third adjustment programme in August 2018. Connectedness with regard to Ireland on the other hand, which started its programme in November 2010, resumed immediately after December 2013; that is, when the country exited its programme. Furthermore, results for Italy may differ since Italy never entered a programme at all. It is worth noting however, that in the most recent observations in our sample, there is a collapse in connectedness between Germany and Italy, probably reflecting uncertainty fueled by recent political frictions between the European Commission and the Italian Government. Portugal entered its programme in May 2011. In turn, connectedness in Portugal strengthened after January 2014; that is, when the country exited its programme. Similar results can be reported for Spain which underwent an economic adjustment programme between June 2012 and January 2014.

[Insert Figure 5 around here]

Considering the connectedness relating to core countries during the crisis, we note that Germany transmits to all of these countries for most of the time with the exception of the months immediately before (and in some cases immediately after) year 2012. There

\footnotetext{
${ }^{4}$ Hereby, we are following authors such as Von Hagen and Fratianni (1990), Von Hagen and Neumann (1994) and Antonakakis et al. (2017). Additionally, it seems also plausible from a theoretical point of view to utilize Germany as reference since the German mark was de facto the European currency unit $(E C U)$ and Germany is the main net pairwise transmitter of shocks as shown in Table 2.
} 
are of course notable discrepancies among core countries as well, when it comes to German transmissions of shocks; such as, the fact that Austria transmits more to Germany compared to Belgium and Finland, or that, France mainly receives, without ever really transmitting to Germany. At the same time, this process is rather balanced for Netherlands. On a final note, in order to further emphasize that transmission patterns are not very clear when countries are distinguished between core and periphery, we concentrate on the most recent months of our sample. As shown in Figure 5 Germany, in the months following 2017, transmits considerably (for example) to both Austria (core) and Portugal (periphery) but less so to both Belgium (core) and Ireland (periphery).

In retrospect, results presented in this section clearly illustrate that it is not always easy to make generalisations on the basis of the customary classification of EMU countries to core and periphery. What is more, on the premise that economies are subject to shocks, identifying the appropriate mechanisms to alleviate imbalances within a diverse group of countries becomes all the more difficult. Understandably, the discussion stirs towards identifying the necessary conditions for putting together an optimal currency area. As previously mentioned, we attempt to identify potential groups of countries that could actually form a successful monetary union, given the results that we from pairwise connectedness indices. The relevant findings are presented in the section that follows.

\subsection{A Connectedness Approach to Forming Groups}

Following the discussion in previous sections, we would like to further investigate whether the customary classification of countries into core and periphery further entails that economic agents conceive of EMU as a union consisting of a rather diverse set of countries. To this end, we utilize pairwise connectedness indices to identify pairs of countries that move much closer with each other and would therefore constitute ideal matches towards making a more sensible union (i.e. higher synchronization). It should be clearly emphasized that, the objective of this exercise is to identify countries that are considered to be equally risky, as the latter is being captured by the degree of their pairwise co-movements.

However, before we discuss the averaged pairwise connectedness values per se, we focus on their time-varying behavior. Figure 6 depicts interconnectedness between all countries 
of interest and Germany. Findings indicate that all countries, except for Austria, have decreased co-movements with the German bond yield during the European government debt crisis (2010). Interestingly though, core countries recovered from their lowest levels in a faster pace whereas the sluggish recoveries of periphery countries - with the exception of Ireland - have not even been close to their pre-crisis levels. Particularly in the case of Greece, we see that the co-movement with the German bond yield broke down completely and there is no evidence of recovery within our sample period. Notably, all periphery countries, except Ireland, decoupled again in 2018 whereas the Italian case seems to be the most pronounced since its interconnectedness dropped to its 2010 level. The repeated decoupling of periphery pairwise connectedness could be a signal of a new imminent crisis.

[Insert Figure 6 around here]

In this respect, Figure 7 illustrates that 16 pairs of countries tend to move closer together which is indicative of the fact that the countries included in these pairs could form a more sensible (i.e., equally risky) union. To put it differently, the intercept of the relevant model changes significantly after the 16th pair. The latter practically implies that after the 16th pair, the bilateral connectedness is clearly decoupled from the others and hence it would not be sensible from a connectedness point of view to consider the ensuing pairs as good matches.

[Insert Figure 7 around here]

Results with regard to specific pairs are given by Table 3. It would be instructive at this point to note that although the analysis in this section refers to the baseline model; that is, to the TVP-VAR(0.99/0.99), Table 3 also reports results from alternative specifications to the effect that a sensitivity/robustness analysis is possible. In addition, robustness analysis is presented in greater detail in the section that follows. On general principles, results are qualitative similar across models. In this respect, concentrating on the first 16 pairs represented in Table 3, turns out that core countries have better chances to constitute good candidates for an equally risky union. Nonetheless, in line with our previous findings, even across core countries there exist noteworthy differences (e.g. the Netherlands-Finland pair, which occupies the top of the relevant column, is apparently 
less diverse than the France-Belgium one, which, by contrast lies at the bottom of that list). These findings could help explain the differences we pointed out in the previous sections. What is also evident in Table 3 is that Spain and Italy might consider setting up a separate union on their own. This finding resonates with Galariotis et al. (2016) and Leschinski and Bertram (2017) who point out that Italy and Spain are the most important when it comes to exerting influence on other EMU member states. Nevertheless, we do not have any evidence that other periphery countries qualify for another monetary union.

\section{[Insert Table 3 around here]}

On general principles, results from this connectedness exercise appear to justify the customary distinction of countries into core and periphery. Apparently, with the exception of Italy and Spain, the top 16 groups exclusively consist of countries from the core. In this regard, given that most periphery countries are not regarded as being equal in terms of risk and future prospects to their core counterparts, then, the extent of integration and effort to mitigate economic asymmetry across member states has so far been rather insufficient.

In turn, existing literature underscores potential problems in close relation to these results. More particularly, in the work of De Grauwe and Ji (2013) and Saka et al. (2015) we find evidence in favour of the fragility hypothesis according to which the European debt crisis (2010) was fueled by self-fulfilling market fear (i.e., regarding the capacity of the EMU to overcome the crisis) that was eventually quelled by ECB's intervention in 2012. A fact that further highlights how crucial the role of the ECB as a lender of last resort has been. With reference to the role of the ECB, authors such as Genschel and Jachtenfuchs (2018) put forward the argument that the very fact that the ECB acted as a lender of last resort implies that currently the Euro Area is practically characterized by a shortfall in internal capacity-building. That is, EMU countries have not yet explicitly developed the necessary mechanisms and the appropriate regulatory framework in order to successfully calm the markets and avert future crises from occurring. Understandably, the lack of capacity-building does not reassure economic agents and does not help mitigate the self-fulfilling expectations hypothesis that is mentioned above. 
Furthermore, as regards the shortfall in regulations, Bayoumi and Eichengreen (2018) stress out that one common supervisor for the European banking and financial system is rather imperative and that the sovereign debt crisis in Europe was also associated with the huge lending in the early years of the adoption of the common currency, from core countries to EMU periphery. The latter has also been underscored in the work of Fingleton et al. (2015) who explicate that given the inherent regional disparities in productivity within the EMU, tranquil periods are advantageous for the European South (i.e., exactly because of the capital transfers mentioned above); however, turbulent periods are further aggravated by these disparities (i.e., which foster market fear and lead to capital flights towards what investors conceive of as safety). Flight to safety (i.e., mainly toward Germany) and its impact on the sovereign debt crisis has also been emphasized by Paniagua et al. (2016).

It follows that the findings of our study - in line with the fragility hypothesis - stress the importance of deeper integration of EMU member states. This deepening should focus on the development of policies and mechanisms that target market fear and rationalize (i.e., justify) capital inflows and outflows across countries. Otherwise, the pairwise connectedness results presented in this study suggest that if the periphery countries of our sample remain in the common currency area, then, the underlying differences and the different perceptions of riskiness across member states, coupled with the lack of appropriate support mechanisms, will merely perpetuate the occurrence of financial crisis episodes. This issue becomes even more relevant in view of the desired expansion of EMU and the accession of new countries.

In consonance with Fingleton et al. (2015) we also argue that nominal integration as currently supported by Maastricht criteria, may not be sufficient to promote economic symmetry across the participants of the Euro Area; and that, real integration, which involves actual growth provisions is in fact, what should matter the most. That is, the Euro Area should act beyond the framework drawn up by the SGP that focuses mainly on regulations pertaining to fiscal imbalances. On a final note, in accordance with Genschel and Jachtenfuchs (2018) we opine that, political initiatives purporting to enhance solidarity across member states by enhancing the sharing of specific disturbances are rather imperative (e.g., explicit decisions regarding the refugee crisis that currently torments 
mostly the Southern countries of Europe).

In retrospect, this study provides evidence - based on pairwise connectedness indices - that sensible currency areas should not include periphery EMU countries. The reason being, that currently, these countries lead to additional asymmetric sovereign bond yield dynamics vis-a-vis to their core counterparts which, by contrast, rather facilitate symmetry in the sovereign bond market. The latter is quite alarming considering the argument that the sovereign debt crisis was associated with self-fulfilling expectations in connection with the capacity to respond and the willingness to resolve the crisis. Evidentially, there is a void in the relevant regulations that is currently being filled by the ECB which acts as the lender of last resort. In this regard, European authorities should consider mechanisms and policies to enhance confidence in the common currency area.

\section{Robustness Check}

Even though the time-varying dynamics of connectedness provide important insights in the transmission mechanism of bond yields, our main interest lies with the creation of a European optimum currency area. To test the validity of our pairwise connectedness results retrieved from the TVP-VAR $(0.99,0.99)$, we provide a battery of robustness checks.

First of all we compare our results against a simple constant coefficient VAR-based connectedness approach on the full sample. In turn, given that a standard VAR model can be seen as an equation-by-equation OLS procedure - which produces conditional mean estimators that are outlier sensitive - we propose a Quantile-VAR where each equation is estimated via quantile regression.

Second, we provide the ranking results based on different TVP-VAR $\left(\kappa_{1}, \kappa_{2}\right)$ specifications. Even though setting both decay factors equal to 0.99 seems to be a reasonable prior-choice we are also interested in capturing different outcomes considering different settings. Hence, as an additional robustness and sensitivity check we allow both decay factors to vary. On the one hand, $\kappa_{1}$ is allowed to be between 0.97 and 0.99 whereas on the other side $\kappa_{2}$ varies between 0.96 and $0.99 .^{5}$

\footnotetext{
${ }^{5}$ Please keep in mind that for analyzing monthly data Koop and Korobilis (2014) set $\kappa_{1}=0.99$ and $\kappa_{2}=0.96$.
} 
Finally, we estimate two DCC-GARCH copula models (Patton, 2006) and employ averaged dynamic conditional correlations - as opposed to average pairwise connectedness indices - as a measure to form groups. Since the pairwise connectedness index can be seen as a measure of co-movement, using dynamic conditional correlations seems to be an appropriate alternative. In addition to the DCC-GARCH Gaussian-copula, we have estimated a DCC-GARCH t-copula which allows for heavy tailed distributions. ${ }^{6}$.

As mentioned earlier in the text, Table 3 shows that all results across models are qualitatively similar. Interestingly, the first 16 pairs of our benchmark model are identical to the first 16 pairs of all alternative models even though rankings sometimes differ. This provides strong evidence of a large European monetary union consisting of Austria, Belgium, Finland, Germany, and the Netherlands and a small European monetary union between Italy and Spain.

\section{Concluding Remarks}

In view of further expansion of the common currency area - given that more countries are expected to adopt the Euro in the future - it is important for research to concentrate on the factors that determine the successful integration of the EMU's diverse participants. Existing studies in the field typically investigate member states convergence, considering a broad spectrum of macroeconomic and financial indicators. In this regard, it is rather customary to investigate the degree of financial risk synchronisation by considering sovereign bond yield spreads or credit default swaps (CDS) contracts. Furthermore, it is also typical to make use of these results in order to propose some insightful classification/clustering of the countries under investigation. Within a much related strand, our study develops an enhanced version of the dynamic connectedness approach in order to test pairwise disparities of sovereign bond yield connectedness across a set of both core and periphery EMU member states over the period from August 2003 and September 2018.

Within the framework of our study, dynamic total connectedness reveals financial risk coordination (e.g., a large value of the pairwise connectedness between two member states

\footnotetext{
${ }^{6}$ As the detailed description of quantile regressions and DCC-GARCH copulas is beyond the scope of this study interested readers are referred to Koenker and Bassett Jr (1978) and Patton (2006), respectively.
} 
implies that they are very close in terms of financial risk; that is, they are influencing each other by the same amount). It follows that we are able to (i) investigate synchronisation or decoupling at the height of the crisis, (ii) identify net transmitters and net receivers of sovereign debt shocks, as well as (iii), utilize connectedness results in order to identify pairs that are better coordinated by virtue of financial risk and that would, therefore, constitute appropriate partners within a currency union. This line of research is rather important given that low levels of coordination of financial risk across member states challenge the notion of the optimal currency area and further question the capacity of the EMU to abate the likelihood of some future sovereign debt crisis.

Results for dynamic total connectedness provide support to the fragmentation argument regarding the variation of spillovers across member states over time (i.e., efforts to reduce financial contagion forestalled interconnectedness across member states). Clearly, interrelations across member states is much higher in the period prior to 2009. By contrast, it is evident that at the height of the crisis, investors question both the capacity and the willingness of the parties involved to resolve the disturbance. Nonetheless, following the ECB's intervention in 2012 connectedness is restored without having thus far reverted to its initial levels. The latter is indicative of the fact that there are still sources of turbulence and uncertainty that corrode confidence within the EMU.

On general principles, findings associated with net total directional connectedness imply that the core is mainly a net transmitter of shocks to the periphery although clearly, this influence wanes (or is even reversed) considerably at the height of the crisis. The positive influence from the core during tranquil times could be related to capital inflows to Southern economies. What is more, periods of very low net connectedness (e.g., Greece immediately after 2012) might be indicative of very strong fragmentation (i.e., core countries managed to immunize themselves against certain stressed economies). Nonetheless, a closer examination of the results reveals that with the exception of Germany - at the height of the crisis but also in the later months of our sample - certain member states may assume either role, irrespective of whether they are core or periphery. This finding, is suggestive of the fact that, the goal of convergence across EMU member states is rather challenging and further questions, whether, the customary distinction between core and 
periphery countries is sensible in terms of financial risk.

To this end, we identify pairs of countries that exhibit high bilateral connectedness levels in order to suggest a sensible currency area. Consistent with the customary distinction, we find that there are 16 'ideal' pairs, dominated indeed by core countries, with the exception of Italy and Spain. In turn, we stress that this finding indicates a weakness for the current structure of the EMU given that periphery countries that do not make the cut of the top 16 pairs, will always be likely sources of uncertainty and market panic, that might trigger future financial crises (i.e., in line with the fragility hypothesis). With reference to the European Commission (2017) White Paper on the Future of Europe, we opine that further integration across EMU members is necessary to secure a more stable structure and hence a more viable future. In agreement with existing relevant literature, we emphasize that part of the current predicaments of the EMU could be resolved by enhanced regulation on the financial sphere and increased solidarity on the political one.

\section{References}

Afonso, A., Arghyrou, M. G., Gadea, M. D., and Kontonikas, A. (2018). "Whatever it takes" to resolve the European sovereign debt crisis? Bond pricing regime switches and monetary policy effects. Journal of International Money and Finance, 86:1-30.

Anscombe, F. J. and Glynn, W. J. (1983). Distribution of the kurtosis statistic b 2 for normal samples. Biometrika, 70(1):227-234.

Antonakakis, N., Christou, C., Cunado, J., and Gupta, R. (2017). Convergence patterns in sovereign bond yield spreads: Evidence from the Euro Area. Journal of International Financial Markets, Institutions and Money, 49:129-139.

Antonakakis, N. and Gabauer, D. (2017). Refined Measures of Dynamic Connectedness based on TVP-VAR. Technical report, University Library of Munich, Germany.

Basse, T. (2014). Searching for the EMU core member countries. European Journal of Political Economy, 34:S32-S39.

Bayoumi, T. and Eichengreen, B. (2018). Aftershocks of Monetary Unification: Hysteresis with a Financial Twist. Journal of Banking $\&$ Finance.

Beetsma, R., de Jong, F., Giuliodori, M., and Widijanto, D. (2017). Realized (co) variances of eurozone sovereign yields during the crisis: The impact of news and the Securities Markets Programme. Journal of International Money and Finance, 75:14-31.

BenSaïda, A. (2018). The contagion effect in European sovereign debt markets: A regimeswitching vine copula approach. International Review of Financial Analysis, 58:153165.

Bhatt, V., Kishor, N. K., and Ma, J. (2017). The impact of EMU on bond yield convergence: Evidence from a time-varying dynamic factor model. Journal of Economic Dynamics and Control, 82(C):206-222.

Bølstad, J. and Elhardt, C. (2018). Capacity, Willingness, and Sovereign Default Risk: Reassuring the Market in Times of Crisis. Journal of Common Market Studies, 56(4):802817.

Bratis, T., Laopodis, N. T., and Kouretas, G. P. (2018). Contagion and interdependence 
in Eurozone bank and sovereign credit markets. International Journal of Finance $\mathcal{E}^{3}$ Economics, 23(4):655-674.

Caporin, M., Pelizzon, L., Ravazzolo, F., and Rigobon, R. (2018). Measuring sovereign contagion in Europe. Journal of Financial Stability, 34:150-181.

Christiansen, C. (2014). Integration of European bond markets. Journal of Banking \& Finance, 42:191-198.

D'Agostino, R. B. (1970). Transformation to normality of the null distribution of g1. Biometrika, pages 679-681.

De Grauwe, P. (2013). The European Central Bank as lender of last resort in the government bond markets. CESifo Economic Studies, 59(3):520-535.

De Grauwe, P. (2016). The legacy of the Eurozone crisis and how to overcome it. Journal of Empirical Finance, 39:147-155.

De Grauwe, P. and Ji, Y. (2013). Self-fulfilling crises in the Eurozone: An empirical test. Journal of International Money and Finance, 34:15-36.

Diebold, F. X. and Yllmaz, K. (2009). Measuring Financial Asset Return And Volatility Spillovers, With Application To Global Equity Markets. Economic Journal, 119(534):158-171.

Diebold, F. X. and Yılmaz, K. (2012). Better to give than to receive: Predictive directional measurement of volatility spillovers. International Journal of Forecasting, 28:57-66.

Diebold, F. X. and Yılmaz, K. (2014). On the network topology of variance decompositions: Measuring the connectedness of financial firms. Journal of Econometrics, 182(1):119-134.

Ehrmann, M. and Fratzscher, M. (2017). Euro area government bonds-Fragmentation and contagion during the sovereign debt crisis. Journal of International Money and Finance, 70:26-44.

Eichengreen, B. (2014). The Eurozone Crisis: The theory of optimum currency areas bites back. Notenstein Academy White Paper Series.

European Commission (2017). White paper on the future of Europe: Reflections and scenarios for the EU27 by 2025. Brussels: European Commission.

Falagiarda, M. and Reitz, S. (2015). Announcements of ECB unconventional programs: Implications for the sovereign spreads of stressed euro area countries. Journal of International Money and Finance, 53:276-295.

Fernández-Rodríguez, F., Gómez-Puig, M., and Sosvilla-Rivero, S. (2016). Using connectedness analysis to assess financial stress transmission in EMU sovereign bond market volatility. Journal of International Financial Markets, Institutions and Money, 43:126145.

Fingleton, B., Garretsen, H., and Martin, R. (2015). Shocking aspects of monetary union: the vulnerability of regions in Euroland. Journal of Economic Geography, 15(5):907934.

Fisher, T. J. and Gallagher, C. M. (2012). New weighted portmanteau statistics for time series goodness of fit testing. Journal of the American Statistical Association, 107(498):777-787.

Galariotis, E. C., Makrichoriti, P., and Spyrou, S. (2016). Sovereign CDS spread determinants and spill-over effects during financial crisis: A panel VAR approach. Journal of Financial Stability, 26:62-77.

Genschel, P. and Jachtenfuchs, M. (2018). From market integration to core state powers: the Eurozone crisis, the refugee crisis and integration theory. Journal of Common Market Studies, 56(1):178-196.

Hodson, D. (2017). Eurozone Governance in 2016: The Italian Banking Crisis, Fiscal Flexibility and Brexit (Plus Plus Plus). Journal of Common Market Studies, 55:118132.

Jäger, J. and Grigoriadis, T. (2017). The effectiveness of the ECB's unconventional monetary policy: Comparative evidence from crisis and non-crisis Euro-area countries. 
Journal of International Money and Finance, 78:21-43.

Jarque, C. M. and Bera, A. K. (1980). Efficient tests for normality, homoscedasticity and serial independence of regression residuals. Economics Letters, 6(3):255-259.

Koenker, R. and Bassett Jr, G. (1978). Regression Quantiles. Econometrica, pages 33-50.

Koop, G. and Korobilis, D. (2013). Large time-varying parameter VARs. Journal of Econometrics, 177(2):185-198.

Koop, G. and Korobilis, D. (2014). A new index of financial conditions. European Economic Review, 71:101-116.

Koop, G., Pesaran, M. H., and Potter, S. M. (1996). Impulse response analysis in nonlinear multivariate models. Journal of Econometrics, 74(1):119-147.

Korobilis, D. and Yilmaz, K. (2018). Measuring Dynamic Connectedness with Large Bayesian VAR Models.

Leschinski, C. and Bertram, P. (2017). Time varying contagion in EMU government bond spreads. Journal of Financial Stability, 29:72-91.

McKinnon, R. I. (1963). Optimum currency areas. American Economic Review, $53(4): 717-725$.

Mundell, R. A. (1961). A theory of optimum currency areas. American Economic Review, $51(4): 657-665$.

O'Rourke, K. H. and Taylor, A. M. (2013). Cross of euros. Journal of Economic Perspectives, 27(3):167-92.

Paniagua, J., Sapena, J., and Tamarit, C. (2016). Sovereign debt spreads in EMU: The time-varying role of fundamentals and market distrust. Journal of Financial Stability.

Patton, A. J. (2006). Modelling asymmetric exchange rate dependence. International Economic Review, 47(2):527-556.

Pesaran, H. H. and Shin, Y. (1998). Generalized impulse response analysis in linear multivariate models. Economics Letters, 58(1):17-29.

Primiceri, G. E. (2005). Time varying structural vector autoregressions and monetary policy. Review of Economic Studies, 72(3):821-852.

Reboredo, J. C. and Ugolini, A. (2015). Systemic risk in European sovereign debt markets: A CoVaR-copula approach. Journal of International Money and Finance, 51:214-244.

Roch, F. and Uhlig, H. (2018). The dynamics of sovereign debt crises and bailouts. Journal of International Economics, 114:1-13.

Saka, O., Fuertes, A.-M., and Kalotychou, E. (2015). ECB policy and Eurozone fragility: Was De Grauwe right? Journal of International Money and Finance, 54:168-185.

Stock, J., Elliott, G., and Rothenberg, T. (1996). Efficient tests for an autoregressive unit root. Econometrica, 64(4):813-836.

Verdun, A. (2018). Institutional Architecture of the Euro Area. Journal of Common Market Studies, 56:74-84.

Von Hagen, J. and Fratianni, M. (1990). German dominance in the EMS: evidence from interest rates. Journal of International Money and Finance, 9(4):358-375.

Von Hagen, J. and Neumann, M. J. (1994). Real exchange rates within and between currency areas: how far away is EMU? Review of Economics and Statistics, pages 236-244. 
Table 1: Summary Statistics: Bond Yield Changes

\begin{tabular}{|c|c|c|c|c|c|c|c|c|c|c|c|}
\hline & Austria & Belgium & Finland & France & Germany & Netherlands & Greece & Ireland & Italy & Portugal & Spain \\
\hline Mean & -0.00093 & -0.00091 & -0.00094 & -0.00098 & -0.00091 & -0.00096 & 0.00012 & -0.00092 & -0.00029 & -0.00061 & -0.00072 \\
\hline Median & -0.00090 & -0.00115 & -0.00110 & -0.00115 & -0.00120 & -0.00120 & 0.00010 & -0.00170 & -0.00040 & -0.00100 & -0.00050 \\
\hline Variance & 0.00170 & 0.00192 & 0.00165 & 0.00164 & 0.00166 & 0.00155 & 0.28326 & 0.00519 & 0.00382 & 0.01137 & 0.00372 \\
\hline Skewness & $\begin{array}{c}0.413 * * * \\
(0.000)\end{array}$ & $\begin{array}{c}0.308 * * * \\
(0.000)\end{array}$ & $\begin{array}{c}0.249 * * * \\
(0.000)\end{array}$ & $\begin{array}{c}0.102 * * * \\
(0.009)\end{array}$ & $\begin{array}{c}0.201 * * * \\
(0.000)\end{array}$ & $\begin{array}{c}0.198 * * * \\
(0.000)\end{array}$ & $\begin{array}{c}-34.664 * * * \\
(0.000)\end{array}$ & $\begin{array}{c}-0.150 * * * \\
(0.000)\end{array}$ & $\begin{array}{c}-0.601 * * * \\
(0.000)\end{array}$ & $\begin{array}{c}1.236 * * * \\
(0.000)\end{array}$ & $\begin{array}{c}-1.012 * * * \\
(0.000)\end{array}$ \\
\hline $\begin{array}{l}\text { Excess } \\
\text { Kurtosis }\end{array}$ & $\begin{array}{c}3.157 * * * \\
(0.000)\end{array}$ & $\begin{array}{c}5.845 * * * \\
(0.000)\end{array}$ & $\begin{array}{c}2.130 * * * \\
(0.000)\end{array}$ & $\begin{array}{c}2.080 * * * \\
(0.000)\end{array}$ & $\begin{array}{c}2.550 * * * \\
(0.000)\end{array}$ & $\begin{array}{c}1.673 * * * \\
(0.000)\end{array}$ & $\begin{array}{c}1826.728 * * * \\
(0.000)\end{array}$ & $\begin{array}{c}32.164 * * * \\
(0.000)\end{array}$ & $\begin{array}{c}18.967 * * * \\
(0.000)\end{array}$ & $\begin{array}{c}49.409 * * * \\
(0.000)\end{array}$ & $\begin{array}{c}18.225 * * * \\
(0.000)\end{array}$ \\
\hline JB & $\begin{array}{c}1737 * * * \\
(0.000)\end{array}$ & $\begin{array}{c}5634 * * * \\
(0.000)\end{array}$ & $\begin{array}{l}781 * * * \\
(0.000)\end{array}$ & $\begin{array}{l}712 * * * \\
(0.000)\end{array}$ & $\begin{array}{c}1087 * * * \\
(0.000)\end{array}$ & $\begin{array}{l}482 * * * \\
(0.000)\end{array}$ & $\begin{array}{c}544982473 * * * \\
(0.000)\end{array}$ & $\begin{array}{c}168727 * * * \\
(0.000)\end{array}$ & $\begin{array}{c}58905 * * * \\
(0.000)\end{array}$ & $\begin{array}{c}399129 * * * \\
(0.000)\end{array}$ & $\begin{array}{c}54837 * * * \\
(0.000)\end{array}$ \\
\hline ERS & $\begin{array}{c}-43.038 * * * \\
(0.000)\end{array}$ & $\begin{array}{c}-40.721 * * * \\
(0.000)\end{array}$ & $\begin{array}{c}-43.648 * * * \\
(0.000)\end{array}$ & $\begin{array}{c}-44.356 * * * \\
(0.000)\end{array}$ & $\begin{array}{c}-44.037 * * * \\
(0.000)\end{array}$ & $\begin{array}{c}-43.601 * * * \\
(0.000)\end{array}$ & $\begin{array}{c}-44.564 * * * \\
(0.000)\end{array}$ & $\begin{array}{c}-36.829 * * * \\
(0.000)\end{array}$ & $\begin{array}{c}-44.516 * * * \\
(0.000)\end{array}$ & $\begin{array}{c}-37.462 * * * \\
(0.000)\end{array}$ & $\begin{array}{c}-41.649 * * * \\
(0.000)\end{array}$ \\
\hline$Q(20)$ & $\begin{array}{c}44.326 * * * \\
(0.000)\end{array}$ & $\begin{array}{c}128.956 * * * \\
\quad(0.000)\end{array}$ & $\begin{array}{c}21.270 * * * \\
(0.010)\end{array}$ & $\begin{array}{c}32.811 * * * \\
(0.000)\end{array}$ & $\begin{array}{c}31.166 * * * \\
(0.000)\end{array}$ & $\begin{array}{c}29.281 * * * \\
(0.000)\end{array}$ & $\begin{array}{c}178.358 * * * \\
(0.000)\end{array}$ & $\begin{array}{c}280.303 * * * \\
(0.000)\end{array}$ & $\begin{array}{c}89.981 * * * \\
(0.000)\end{array}$ & $\begin{array}{c}336.424 * * * \\
\quad(0.000)\end{array}$ & $\begin{array}{c}216.141 * * * \\
(0.000)\end{array}$ \\
\hline \multirow[t]{2}{*}{$\operatorname{LM}(20)$} & $\begin{array}{c}234.001 * * * * \\
(0.000)\end{array}$ & $\begin{array}{c}453.241 * * * * \\
(0.000)\end{array}$ & $\begin{array}{c}134.367 * * * * \\
(0.000)\end{array}$ & $\begin{array}{c}152.724 * * * * \\
(0.000)\end{array}$ & $\begin{array}{c}285.833 * * * \\
(0.000)\end{array}$ & $\begin{array}{c}140.032 * * * \\
(0.000)\end{array}$ & $\begin{array}{c}15.917 * * \\
(0.086) \\
\end{array}$ & $\begin{array}{c}297.497 * * * \\
(0.000)\end{array}$ & $\begin{array}{c}299.260 * * * \\
(0.000) \\
\end{array}$ & $\begin{array}{c}201.494 * * * \\
(0.000)\end{array}$ & $\begin{array}{c}152.599 * * * * \\
(0.000)\end{array}$ \\
\hline & \multicolumn{11}{|c|}{ Unconditional Correlations } \\
\hline Austria & 1.000 & 0.815 & 0.847 & 0.813 & 0.898 & 0.864 & 0.014 & 0.348 & 0.421 & 0.193 & 0.428 \\
\hline Belgium & 0.815 & 1.000 & 0.726 & 0.665 & 0.842 & 0.752 & 0.054 & 0.445 & 0.582 & 0.274 & 0.562 \\
\hline Finland & 0.847 & 0.726 & 1.000 & 0.917 & 0.847 & 0.919 & -0.003 & 0.316 & 0.301 & 0.153 & 0.325 \\
\hline France & 0.813 & 0.665 & 0.917 & 1.000 & 0.814 & 0.909 & -0.033 & 0.261 & 0.226 & 0.106 & 0.258 \\
\hline Germany & 0.898 & 0.842 & 0.847 & 0.814 & 1.000 & 0.878 & 0.016 & 0.352 & 0.475 & 0.198 & 0.458 \\
\hline Netherlands & 0.864 & 0.752 & 0.919 & 0.909 & 0.878 & 1.000 & -0.008 & 0.315 & 0.333 & 0.155 & 0.342 \\
\hline Greece & 0.014 & 0.054 & -0.003 & -0.033 & 0.016 & -0.008 & 1.000 & 0.119 & 0.099 & 0.153 & 0.125 \\
\hline Ireland & 0.348 & 0.445 & 0.316 & 0.261 & 0.352 & 0.315 & 0.119 & 1.000 & 0.420 & 0.485 & 0.454 \\
\hline Italy & 0.421 & 0.582 & 0.301 & 0.226 & 0.475 & 0.333 & 0.099 & 0.420 & 1.000 & 0.382 & 0.784 \\
\hline Portugal & 0.193 & 0.274 & 0.153 & 0.106 & 0.198 & 0.155 & 0.153 & 0.485 & 0.382 & 1.000 & 0.395 \\
\hline Spain & 0.428 & 0.562 & 0.325 & 0.258 & 0.458 & 0.342 & 0.125 & 0.454 & 0.784 & 0.395 & 1.000 \\
\hline
\end{tabular}

Notes: $* * * * * *$ denote significance at $1 \%, 5 \%$ and $10 \%$ significance level; Skewness: D'Agostino (1970) test; Kurtosis: Anscombe and Glynn (1983) test; JB: Jarque and Bera (1980) normality test; ERS: Stock et al. (1996) unit-root test; Q(20) and LM(20): Fisher and Gallagher (2012) weighted portmanteau test.

Table 2: Averaged Dynamic Connectedness Table

\begin{tabular}{|c|c|c|c|c|c|c|c|c|c|c|c|c|}
\hline & Austria & Belgium & Finland & France & Germany & Netherlands & Greece & Ireland & Italy & Portugal & Spain & FROM \\
\hline Austria & 17.6 & 11.7 & 11.9 & 10.8 & 13.7 & 12.4 & 2.7 & 5.7 & 5.1 & 3.6 & 4.8 & 82.4 \\
\hline Belgium & 11.6 & 19.0 & 9.5 & 8.7 & 12.5 & 10.2 & 2.8 & 6.5 & 7.9 & 4.2 & 7.0 & 81.0 \\
\hline Finland & 11.8 & 9.7 & 17.1 & 13.8 & 11.8 & 13.9 & 2.6 & 6.0 & 4.9 & 3.6 & 4.8 & 82.9 \\
\hline France & 11.4 & 9.2 & 14.6 & 17.9 & 11.5 & 14.3 & 2.8 & 5.6 & 4.6 & 3.5 & 4.6 & 82.1 \\
\hline Germany & 13.2 & 12.0 & 11.5 & 10.5 & 17.0 & 12.4 & 2.6 & 6.0 & 5.6 & 3.9 & 5.3 & 83.0 \\
\hline Netherlands & 12.0 & 10.0 & 13.7 & 13.3 & 12.5 & 16.8 & 2.7 & 5.7 & 5.0 & 3.6 & 4.6 & 83.2 \\
\hline Greece & 3.5 & 3.7 & 3.5 & 4.2 & 3.4 & 3.7 & 51.7 & 5.4 & 6.8 & 8.1 & 6.1 & 48.3 \\
\hline Ireland & 6.2 & 7.9 & 6.9 & 6.3 & 7.1 & 6.6 & 4.7 & 27.8 & 9.2 & 8.3 & 9.1 & 72.2 \\
\hline Italy & 5.8 & 8.8 & 5.7 & 5.2 & 6.9 & 5.9 & 4.6 & 8.3 & 24.0 & 8.9 & 15.8 & 76.0 \\
\hline Portugal & 4.3 & 5.4 & 4.6 & 4.2 & 5.1 & 4.5 & 6.4 & 9.4 & 11.5 & 33.4 & 11.3 & 66.6 \\
\hline Spain & 5.6 & 8.2 & 5.7 & 5.3 & 6.6 & 5.5 & 4.3 & 8.6 & 16.5 & 9.0 & 24.8 & 75.2 \\
\hline Contribution TO others & 85.3 & 86.5 & 87.7 & 82.4 & 91.1 & 89.5 & 36.3 & 67.2 & 77.0 & 56.7 & 73.5 & 833.1 \\
\hline NET directional connectedness & 2.9 & 5.5 & 4.7 & 0.3 & 8.0 & 6.3 & -12.0 & -5.1 & 1.0 & -9.9 & -1.7 & TCI \\
\hline NPDC transmitter & 6.0 & 8.0 & 7.0 & 5.0 & 10.0 & 9.0 & 0.0 & 2.0 & 4.0 & 1.0 & 3.0 & 83.3 \\
\hline
\end{tabular}

Notes: Results are based on a TVP-VAR(0.99,0.99) model with lag length of order 1 (BIC) and a 10-step-ahead forecast. 
Table 3: Ranking Based On VAR, Quantile-VAR, TVP-VAR and DCC-GARCH Copula Models

\begin{tabular}{|c|c|c|c|c|}
\hline Rank & TVP-VAR(0.99/0.99) & TVP-VAR $(0.99 / 0.98)$ & TVP-VAR $(0.99 / 0.97)$ & TVP-VAR(0.99/0.96) \\
\hline 1 & Netherlands-Finland & Netherlands-Finland & France-Finland & France-Finland \\
\hline 2 & France-Finland & France-Finland & Netherlands-Finland & Netherlands-Finland \\
\hline 3 & Netherlands-France & Netherlands-France & Netherlands-France & Netherlands-France \\
\hline 4 & Germany-Austria & Germany-Austria & Germany-Austria & Germany-Austria \\
\hline 5 & Netherlands-Germany & Netherlands-Germany & Netherlands-Germany & Netherlands-Germany \\
\hline 6 & Netherlands-Austria & Netherlands-Austria & Netherlands-Austria & Netherlands-Austria \\
\hline 7 & Germany-Belgium & Germany-Belgium & Germany-Belgium & Germany-Belgium \\
\hline 8 & Germany-Finland & Germany-Finland & Germany-Finland & Germany-Finland \\
\hline 9 & Finland-Austria & Finland-Austria & Finland-Austria & Finland-Austria \\
\hline 10 & Belgium-Austria & Spain-Italy & Germany-France & Germany-France \\
\hline 11 & Spain-Italy & Belgium-Austria & Belgium-Austria & Belgium-Austria \\
\hline 12 & Germany-France & Germany-France & Spain-Italy & Spain-Italy \\
\hline 13 & France-Austria & France-Austria & France-Austria & France-Austria \\
\hline 14 & Netherlands-Belgium & Netherlands-Belgium & Netherlands-Belgium & Netherlands-Belgium \\
\hline 15 & Finland-Belgium & Finland-Belgium & Finland-Belgium & Finland-Belgium \\
\hline 16 & France-Belgium & France-Belgium & France-Belgium & France-Belgium \\
\hline Rank & TVP-VAR(0.98/0.99) & TVP-VAR(0.98/0.98) & TVP-VAR(0.98/0.97) & TVP-VAR $(0.98 / 0.96)$ \\
\hline 1 & Netherlands-Finland & Netherlands-Finland & Netherlands-Finland & France-Finland \\
\hline 2 & France-Finland & France-Finland & France-Finland & Netherlands-Finland \\
\hline 3 & Netherlands-France & Netherlands-France & Netherlands-France & Netherlands-France \\
\hline 4 & Germany-Austria & Germany-Austria & Germany-Austria & Germany-Austria \\
\hline 5 & Netherlands-Germany & Netherlands-Germany & Netherlands-Germany & Netherlands-Germany \\
\hline 6 & Netherlands-Austria & Netherlands-Austria & Netherlands-Austria & Netherlands-Austria \\
\hline 7 & Germany-Belgium & Germany-Belgium & Germany-Belgium & Germany-Belgium \\
\hline 8 & Germany-Finland & Germany-Finland & Germany-Finland & Germany-Finland \\
\hline 9 & Finland-Austria & Finland-Austria & Finland-Austria & Finland-Austria \\
\hline 10 & Spain-Italy & Spain-Italy & Germany-France & Germany-France \\
\hline 11 & Belgium-Austria & Belgium-Austria & Spain-Italy & Belgium-Austria \\
\hline 12 & Germany-France & Germany-France & Belgium-Austria & Spain-Italy \\
\hline 13 & France-Austria & France-Austria & France-Austria & France-Austria \\
\hline 14 & Netherlands-Belgium & Netherlands-Belgium & Netherlands-Belgium & Netherlands-Belgium \\
\hline 15 & Finland-Belgium & Finland-Belgium & Finland-Belgium & Finland-Belgium \\
\hline 16 & France-Belgium & France-Belgium & France-Belgium & France-Belgium \\
\hline Rank & TVP-VAR $(0.97 / 0.99)$ & TVP-VAR $(0.97 / 0.98)$ & TVP-VAR $(0.97 / 0.97)$ & TVP-VAR $(0.97 / 0.96)$ \\
\hline 1 & Netherlands-Finland & Netherlands-Finland & Netherlands-Finland & Netherlands-Finland \\
\hline 2 & France-Finland & France-Finland & France-Finland & France-Finland \\
\hline 3 & Netherlands-France & Netherlands-France & Netherlands-France & Netherlands-France \\
\hline 4 & Germany-Austria & Germany-Austria & Germany-Austria & Germany-Austria \\
\hline 5 & Netherlands-Germany & Netherlands-Germany & Netherlands-Germany & Netherlands-Germany \\
\hline 6 & Netherlands-Austria & Netherlands-Austria & Netherlands-Austria & Netherlands-Austria \\
\hline 7 & Germany-Belgium & Germany-Belgium & Germany-Belgium & Germany-Belgium \\
\hline 8 & Germany-Finland & Germany-Finland & Germany-Finland & Germany-Finland \\
\hline 9 & Finland-Austria & Finland-Austria & Finland-Austria & Finland-Austria \\
\hline 10 & Spain-Italy & Spain-Italy & Germany-France & Germany-France \\
\hline 11 & Belgium-Austria & Belgium-Austria & Spain-Italy & Belgium-Austria \\
\hline 12 & Germany-France & Germany-France & Belgium-Austria & Spain-Italy \\
\hline 13 & France-Austria & France-Austria & France-Austria & France-Austria \\
\hline 14 & Netherlands-Belgium & Netherlands-Belgium & Netherlands-Belgium & Netherlands-Belgium \\
\hline 15 & Finland-Belgium & Finland-Belgium & Finland-Belgium & Finland-Belgium \\
\hline 16 & France-Belgium & France-Belgium & France-Belgium & France-Belgium \\
\hline Rank & VAR & Quantile-VAR & DCC-GARCH Gaussian-Copula & DCC-GARCH t-Copula \\
\hline 1 & Netherlands-Finland & Netherlands-Finland & Netherlands-Finland & France-Finland \\
\hline 2 & France-Finland & France-Finland & France-Finland & Netherlands-Finland \\
\hline 3 & Netherlands-France & Netherlands-France & Netherlands-France & Netherlands-France \\
\hline 4 & Germany-Austria & Germany-Austria & Netherlands-Germany & Netherlands-Germany \\
\hline 5 & Netherlands-Germany & Netherlands-Germany & Germany-Austria & Germany-Austria \\
\hline 6 & Netherlands-Austria & Netherlands-Austria & Netherlands-Austria & Netherlands-Austria \\
\hline 7 & Germany-Finland & Germany-Finland & Germany-Belgium & Germany-Belgium \\
\hline 8 & Finland-Austria & Finland-Austria & Germany-Finland & Germany-Finland \\
\hline 9 & Germany-Belgium & Germany-Belgium & Finland-Austria & Finland-Austria \\
\hline 10 & Germany-France & Belgium-Austria & Germany-France & Germany-France \\
\hline 11 & France-Austria & Germany-France & Belgium-Austria & Belgium-Austria \\
\hline 12 & Belgium-Austria & France-Austria & France-Austria & France-Austria \\
\hline 13 & Spain-Italy & Spain-Italy & Spain-Italy & Spain-Italy \\
\hline 14 & Netherlands-Belgium & Netherlands-Belgium & Netherlands-Belgium & Netherlands-Belgium \\
\hline 15 & Finland-Belgium & Finland-Belgium & Finland-Belgium & Finland-Belgium \\
\hline 16 & France-Belgium & France-Belgium & France-Belgium & France-Belgium \\
\hline
\end{tabular}

Notes: Estimation of the $\operatorname{VAR}(1)$ and Quantile-VAR(1) is based on the full sample. DCC-GARCH(1,1) Gaussian and t-copula averaged dynamic conditional correlation measures are used as alternative to VAR-based model connectedness measures. Finally, various TVP-VAR $\left(\kappa_{1}, \kappa_{2}\right)$ results are provided as robustness check to benchmark model. VAR-based results use a lag length of order 1 (BIC) and a 10-step-ahead forecast. 
Figure 1: Sovereign Bond Yields

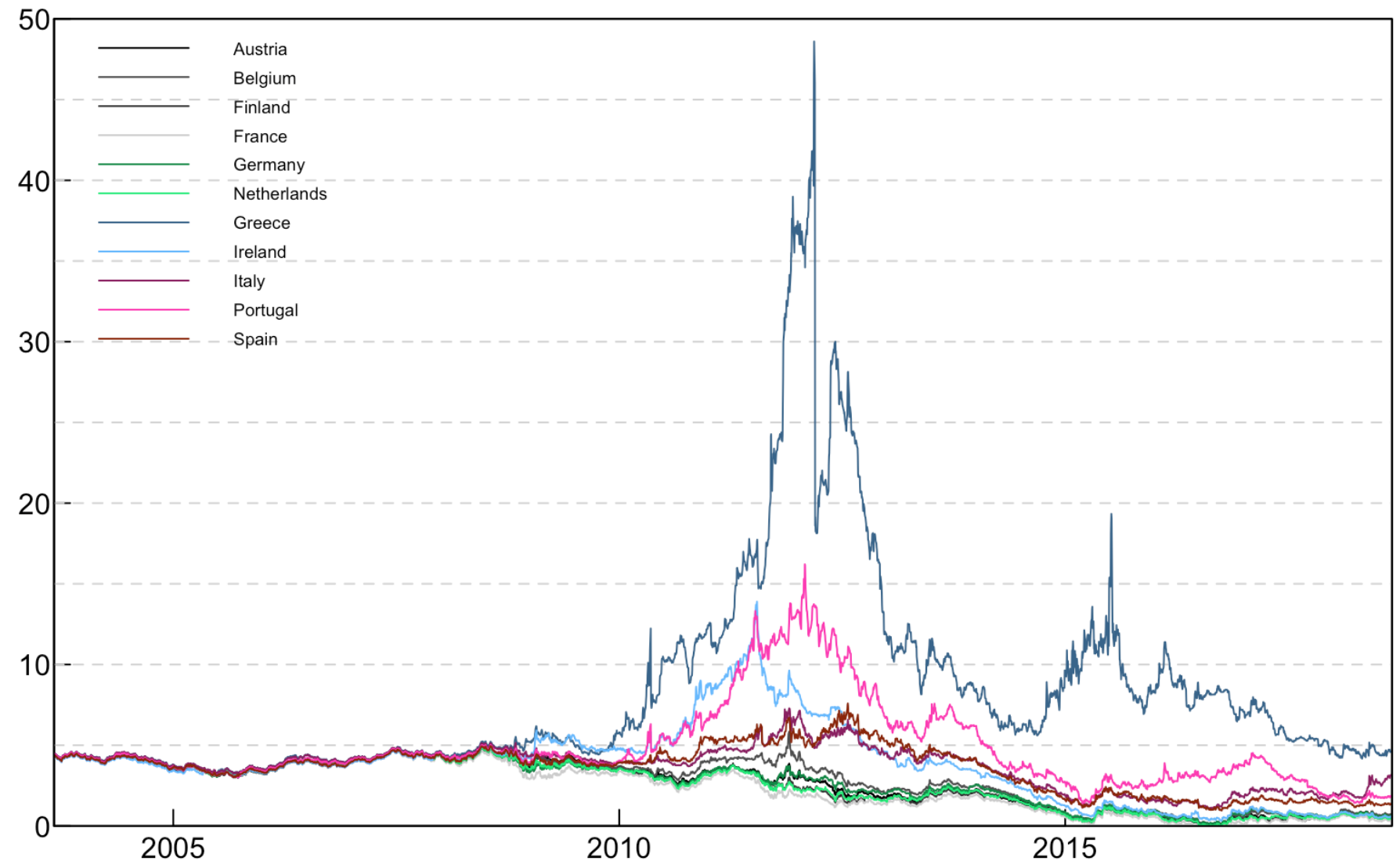

Figure 2: Sovereign Bond Yield Changes
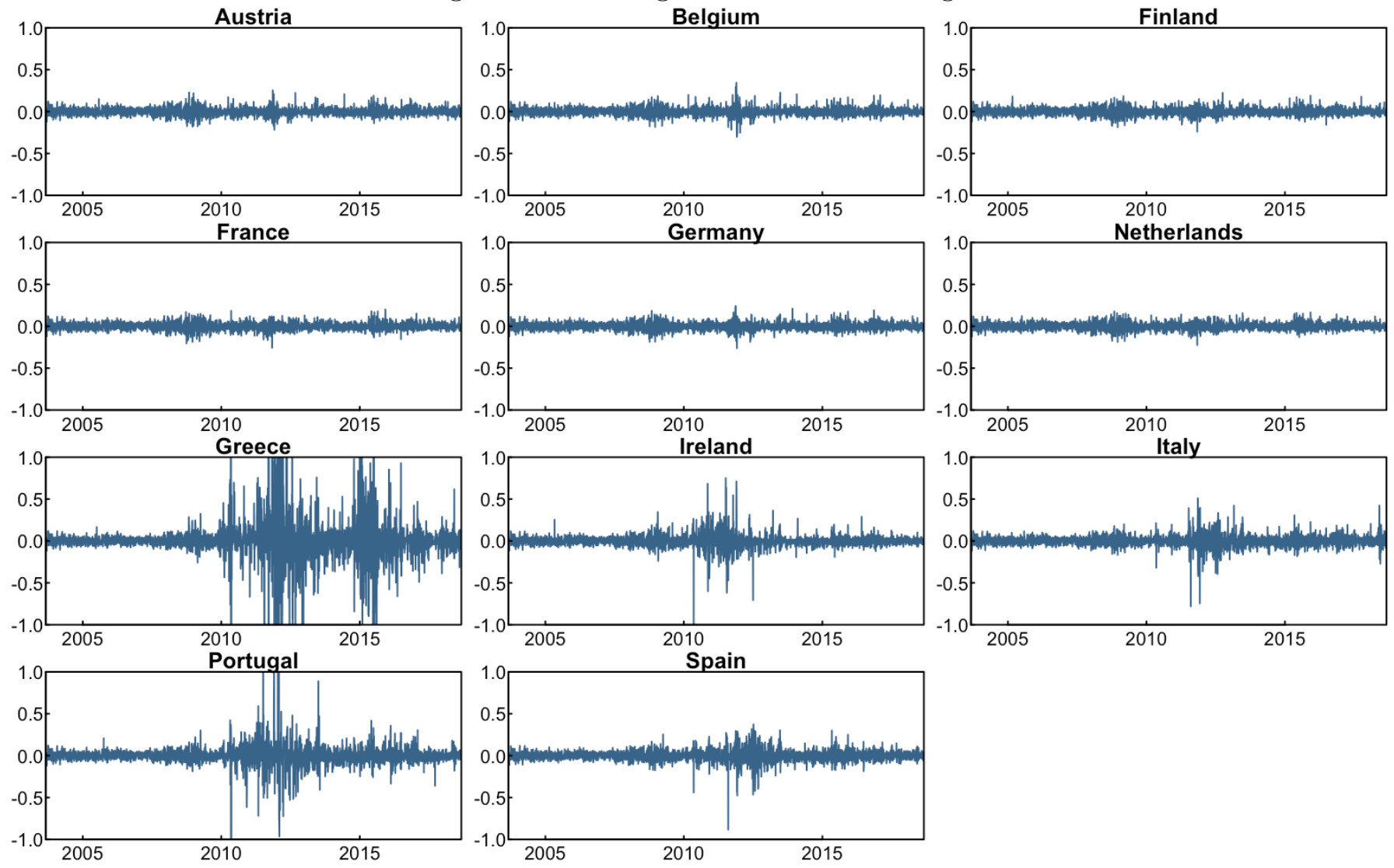
Figure 3: Dynamic Total Connectedness

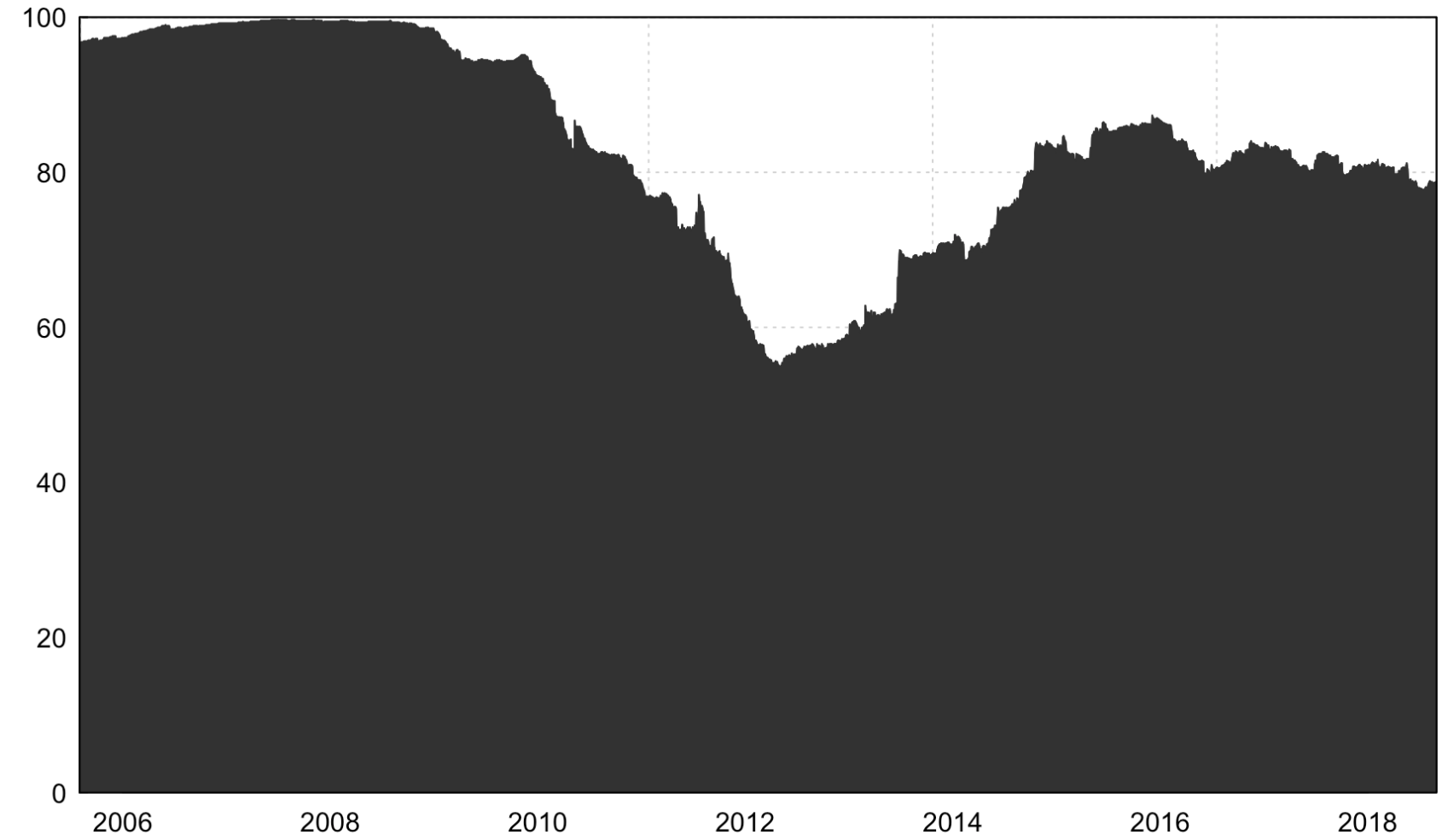

Notes: Results are based on a TVP-VAR(0.99,0.99) model with lag length of order 1 (BIC) and a 10-step-ahead forecast.

Figure 4: Net Total Directional Connectedness
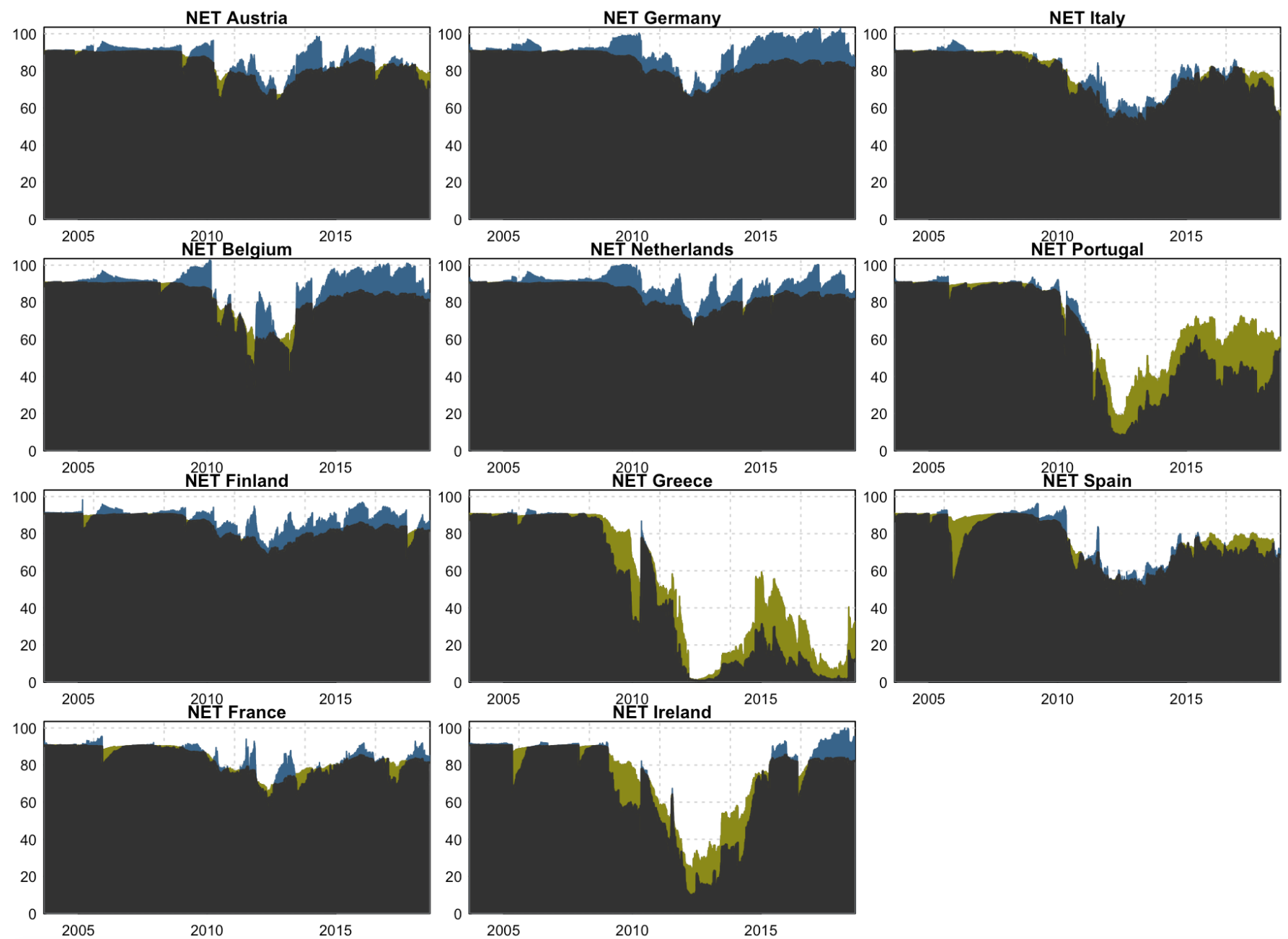

Notes: The black areas represent the overlap of the dynamic total directional connectedness TO and FROM others. A positive net total connectedness is marked blue $\left(T O_{i}>F R O M_{i}\right)$ whereas a negative net total connectedness is marked yellow $\left(T O_{i}<F R O M_{i}\right)$. Results are based on a TVP-VAR $(0.99,0.99)$ with one lag. 
Figure 5: Net Pairwise Directional Connectedness
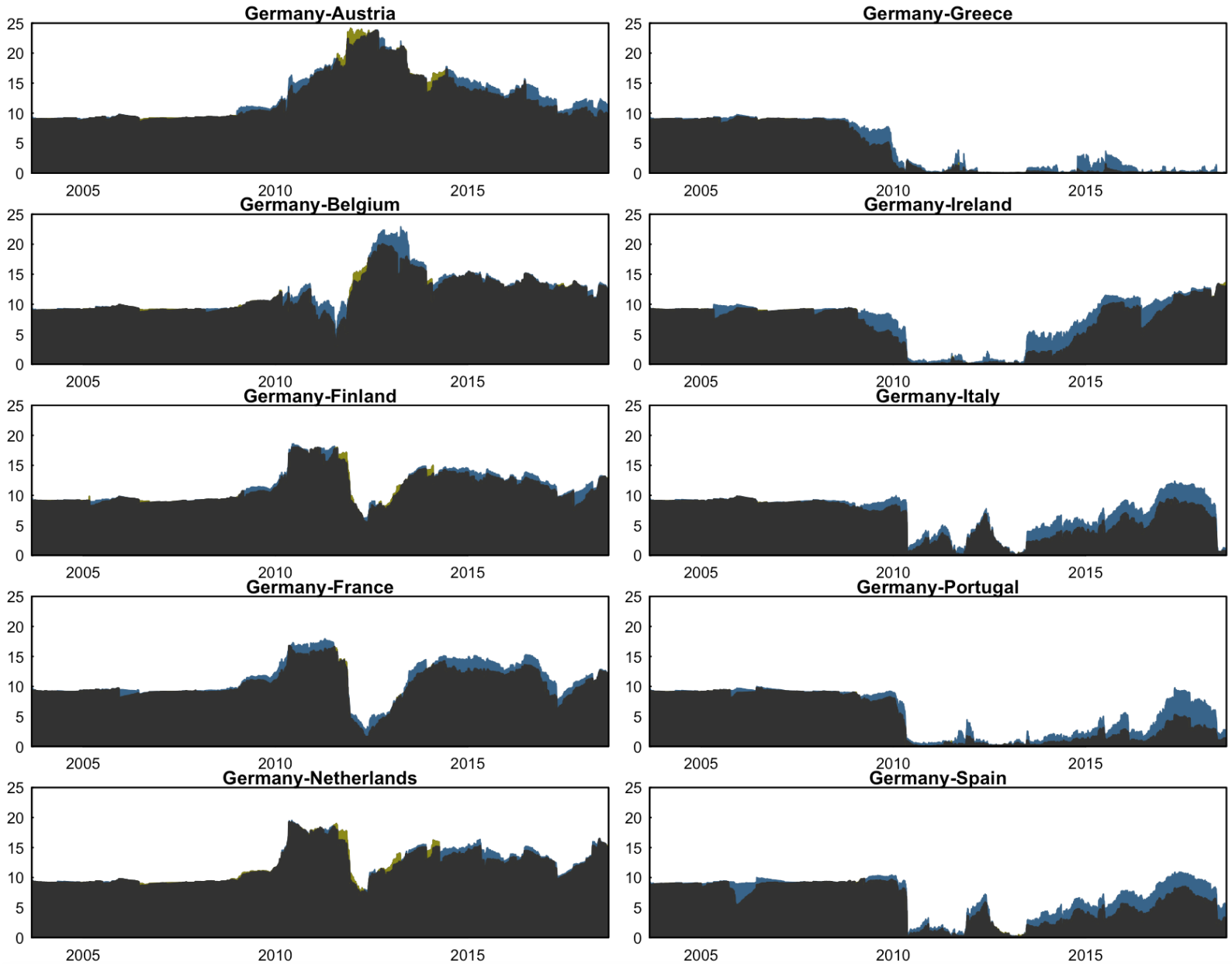

Notes: The black areas represent the overlap of the dynamic pairwise directional connectedness Germany transmits TO and receives FROM $i$. A positive net pairwise connectedness is marked blue $\left(T O_{\text {Germany }}>F R O M_{i}\right)$ whereas a negative net total connectedness is marked yellow $\left(T O_{\text {Germany }}<F R O M_{i}\right)$. Results are based on a TVP-VAR $(0.99,0.99)$ with one lag.

Figure 6: Pairwise Connectedness Index
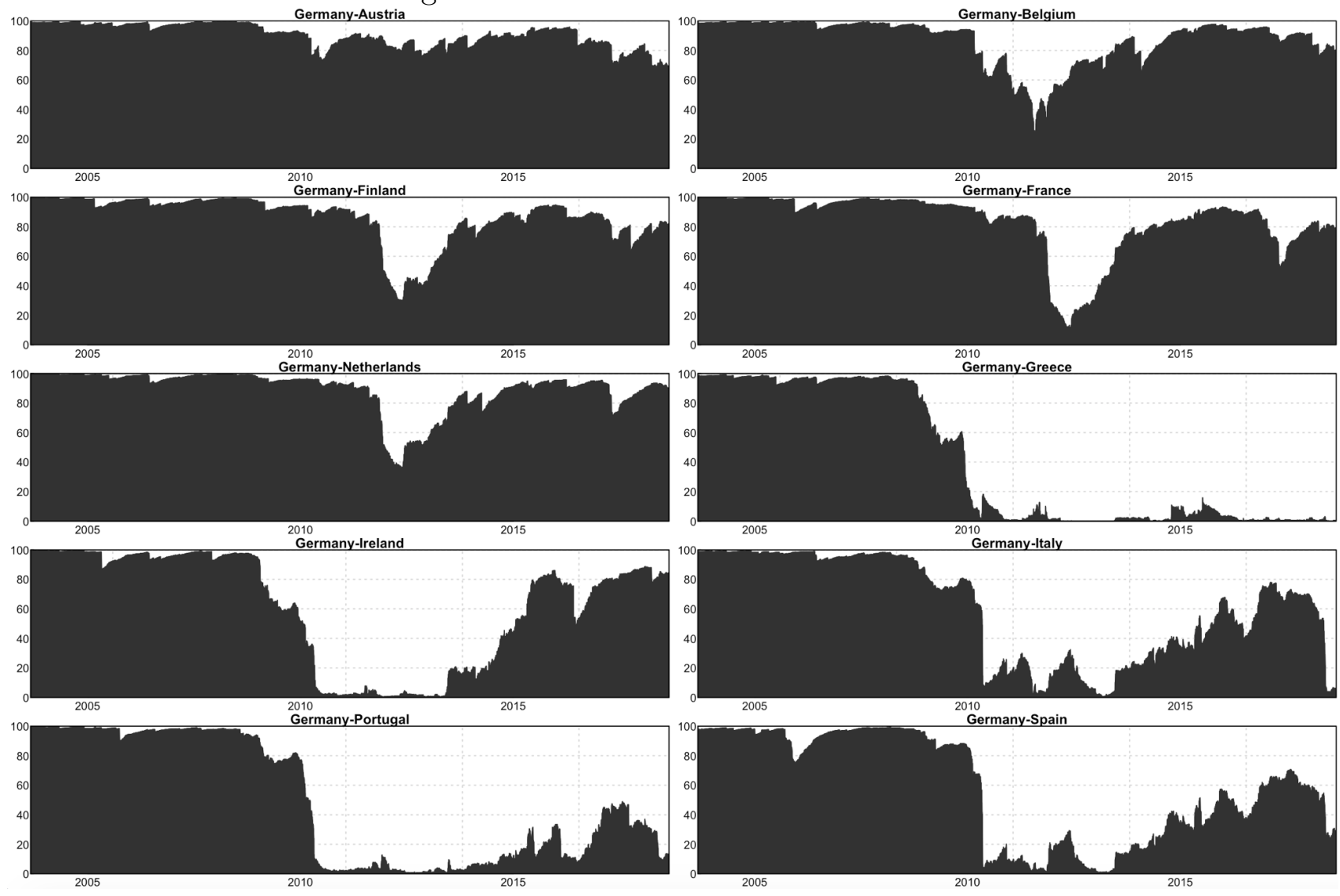
Figure 7: Forming Groups Based On Pairwise Connectedness Indices

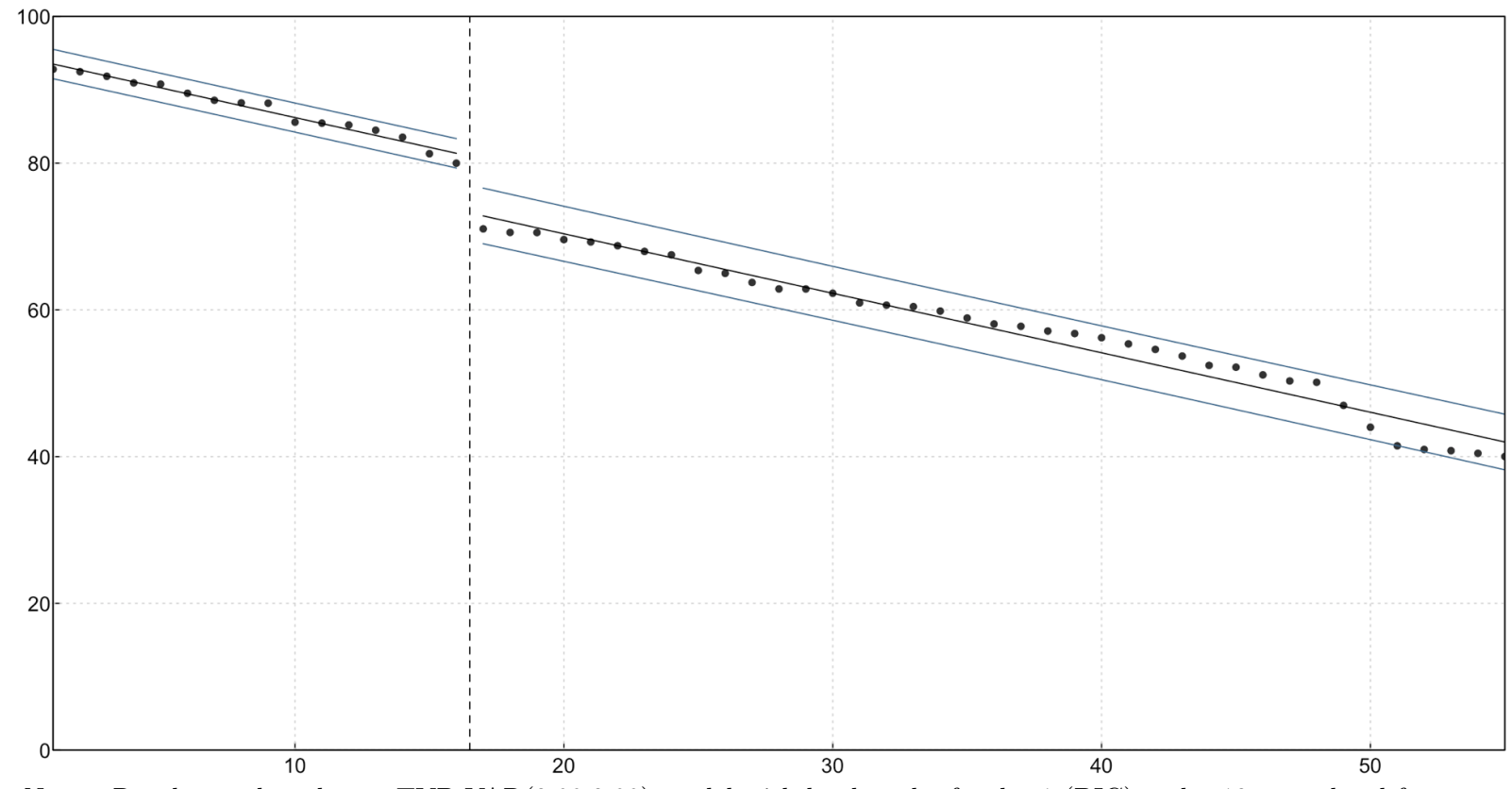

Notes: Results are based on a TVP-VAR(0.99,0.99) model with lag length of order 1 (BIC) and a 10-step-ahead forecast. 